\title{
Make yourselves scarce: The effect of demographic change on the relative wages and employment rates of experienced workers
}

Citation for published version (APA):

Böhm, M. J., \& Siegel, C. (2019). Make yourselves scarce: The effect of demographic change on the relative wages and employment rates of experienced workers. Maastricht University, Graduate School of Business and Economics. GSBE Research Memoranda No. 008 https://doi.org/10.26481/umagsb.2019008

Document status and date:

Published: 02/04/2019

DOI:

10.26481/umagsb.2019008

Document Version:

Publisher's PDF, also known as Version of record

Please check the document version of this publication:

- A submitted manuscript is the version of the article upon submission and before peer-review. There can be important differences between the submitted version and the official published version of record.

People interested in the research are advised to contact the author for the final version of the publication, or visit the DOI to the publisher's website.

- The final author version and the galley proof are versions of the publication after peer review.

- The final published version features the final layout of the paper including the volume, issue and page numbers.

Link to publication

\footnotetext{
General rights rights.

- You may freely distribute the URL identifying the publication in the public portal. please follow below link for the End User Agreement:

www.umlib.nl/taverne-license

Take down policy

If you believe that this document breaches copyright please contact us at:

repository@maastrichtuniversity.nl

providing details and we will investigate your claim.
}

Copyright and moral rights for the publications made accessible in the public portal are retained by the authors and/or other copyright owners and it is a condition of accessing publications that users recognise and abide by the legal requirements associated with these

- Users may download and print one copy of any publication from the public portal for the purpose of private study or research.

- You may not further distribute the material or use it for any profit-making activity or commercial gain

If the publication is distributed under the terms of Article 25fa of the Dutch Copyright Act, indicated by the "Taverne" license above, 
Michael J. Böhm, Christian Siegel

Make Yourselves Scarce: The Effect of Demographic Change on the Relative Wages and Employment Rates of Experienced Workers

RM/19/008

\section{GSBE}

Maastricht University School of Business and Economics

Graduate School of Business and Economics

P.O Box 616

NL- 6200 MD Maastricht

The Netherlands 


\title{
Make Yourselves Scarce: The Effect of Demographic Change on the Relative Wages and Employment Rates of Experienced Workers
}

\author{
Michael J. Böhm and Christian Siegel *
}

March 2019

\begin{abstract}
We argue that rising supply of experience not only reduces experienced workers' relative wages but also their relative labor market participation. From a theoretical model we derive predictions which we quasi-experimentally investigate, using variation across U.S. local labor markets (LLMs) over the last decades and instrumenting experience supply by the LLMs' age structures a decade earlier. We find that aging substantially reduces experienced workers' relative wages and employment rates, and also their labor market participation rates. Our results imply that the effect of demographic change on labor markets might be more severe than previously recognized, as it reaches beyond wages.
\end{abstract}

Keywords: Demographic Change, Employment of Experienced Workers, Return to Experience

JEL codes: J11, J21, J31

* Böhm: University of Bonn and IZA, mboehm1@uni-bonn.de. Siegel: University of Kent and ROA, c.siegel@kent.ac.uk. We wish to thank Antonio Ciccone; Joshua Gottlieb; Georg Graetz; David Green; Thomas Lemieux; Iourii Manovskii; Kevin Milligan; Bryant Kim; and seminar participants at Aalto, HU Berlin, Bonn, Centre for Economic Performance (LSE), Kent, Mannheim, UBC, and Uppsala; and participants at the IZA Junior/Senior Symposium 2016, the SPP conference on "Occupations, Skills, and the Labor Market" in Mannheim 2016, and the ROA Workshop on "Dynamics of Skills Supply and Demand" in Maastricht 2018 for very helpful comments on this project. Böhm gratefully acknowledges support from a Research Fellowship of the German Science Foundation (BO 4765/1-2). 


\section{Introduction}

Many developed economies have experienced a rapid aging of their workforces. In the United States the share of workers above age forty increased over the last decades from under 40 to almost 55 percent (see Figure 1). This demographic change has substantial effects on the labor market by changing relative supplies of older and younger (or experienced and inexperienced) workers, and thereby on their relative wages (e.g. Welch, 1979; Katz and Murphy, 1992; Jeong, Kim, and Manovskii, 2015). But, as long as labor supply is not completely inelastic, the effect on wages implies that demographic change should also affect the fraction of experienced workers who are in employment. This would signify that the overall impact on labor market outcomes of older versus younger individuals may reach far beyond what can be seen in wages alone.

Figure 1: Share of Older Workers and Average Experience in the U.S. (1950-2010)

(a) Share of older full-time workers

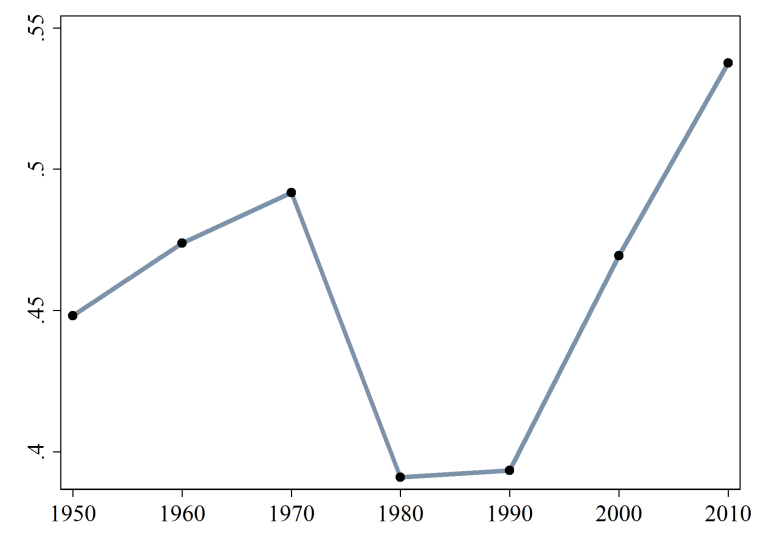

(b) Average years of potential experience

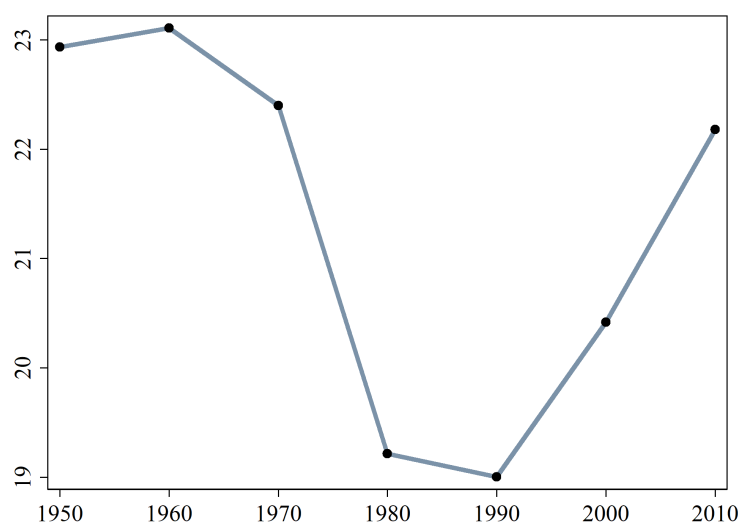

The left panel shows the share of 'younger', age 16 to 40, to 'older', age 41 to 65 , full-time workers. The right panel shows the average years of potential experience of full-time workers, computed as age minus years of schooling minus six.

In this paper we study both the effect of demographic change on relative wages as well as on relative employment rates of experienced workers; a topic the literature has not explored. We use a theoretical model to derive predictions and to guide our empirical approach. In U.S. Census data, we find that increased experience supply not only reduces experienced workers' relative wages, but also the relative fraction of experienced individuals in employment compared to inexperienced individuals, confirming our model's predictions. 
These results are potentially very important for policy design, especially of oldage benefits systems, as they highlight that (experienced) workers' participation rates should not be viewed as constants nor as following secular trends alone. Instead our findings imply that a more abundant group has a lower employment rate, which raises flags that the overall pressure from the aging of the baby boom cohort on social security systems might be larger than what projections based on exogenous participation rates would predict. Another implication of our finding is that aging affects labor market inequality across generations, with larger cohorts facing relatively lower employment and wage rates than smaller cohorts, ceteris paribus. Nonetheless, our results also suggest that demand shifts at the aggregate level over the last decades have been biased in favor of experience (e.g. due to experience-biased technical change as also argued by Caselli, 2015). This prevented the wage return to experience from falling, despite the overall pronounced increase in experience supply.

The second contribution of our paper is empirical. It is difficult to study the effect of demographic change on experienced workers' relative wages and especially employment rates in aggregate data, since important other variables (including technology, policy, and society) change at the same time. We therefore devise a new identification strategy in this context, based on the differential aging of local labor markets. In particular, we construct an instrumental variable for local experience, which exploits the largely predetermined age structure and which allows us to estimate the causal effects of experience supply.

We draw on the recent model of Jeong, Kim, and Manovskii (2015), which we augment with an employment margin. Labor demand stems from a production technology that combines units of experienced and inexperienced labor with a constant elasticity of substitution. The overall supplies of experienced and inexperienced labor inputs are the summation of individual workers' supplies and can be aggregated from individual-level wage equations. We apply this framework to the local labor market level and extend it by adding an employment decision. In particular, an individuallevel reservation wage is introduced, which we allow to depend on demographic and skill characteristics as well as on experience (or age conditional on education). Workers decide to be employed when their labor market earnings exceed the reservation wage. 
We use this model to first derive how in theory demographic change affects the price and the employment gradient of experience, which describe respectively by how much wages and the probability of employment vary with a worker's experience. Then we use this framework to guide our empirical analysis, where an important strength is that the estimated experience price and gradient can be cleaned of confounding wage and employment determinants such as education, race, or gender. However, the key advantage is that it yields one single price and one single employment gradient of experience (both determined by local supply and demand) that fully describe relative wages and employment rates of more experienced compared to less experienced workers. ${ }^{1}$ Note that in the following we use the terms price of experience, wage return to experience, and relative wage of experienced workers largely interchangeably, and similarly the terms employment gradient of experience and relative employment rates of experienced workers.

Unlike previous studies of the impact of demographic change, we implement our empirical analysis at the local labor market level in order to study these supply effects quasi-experimentally. Using data from the U.S. decennial census and the American Community Survey (ACS), we first define local labor markets (LLMs) as the 722 commuting zones of the contiguous United States, as used in Autor and Dorn (2012) and Autor, Dorn, and Hanson (2013), who studied demand shocks. We then also explore a version in which LLMs are the U.S. states. Our estimation sample is decennial from 1980 to 2010 for the commuting zones and from 1960 to 2010 for the U.S. states. In line with Autor, Dorn, and coauthors we treat commuting zones as sub-economies for which we can observe market equilibrium outcomes in different points in time.

A limitation of the census data is that it does not provide actual labor market experience. We construct a measure of potential experience, but it is not possible to distinguish between age and potential experience conditional on education. However, this is not a severe problem for our analysis because we are interested in the effect of demographic change on the labor market, whether this comes from imperfect substi-

\footnotetext{
${ }^{1} \mathrm{Had}$ we grouped workers based on their experience into $N$ discrete groups, we would need to analyze $N(N-1) / 2$ relative wages and relative employment rates, as opposed to one experience price and one gradient. The Jeong, Kim, and Manovskii (2015) setup also improves statistical power compared to grouping workers into discrete experience bins, as it allows to use the fine-grained variation in different years of experience in the individual-level wage and choice regressions explained below.
} 
tutability of old and young workers or of experienced and inexperienced labor inputs.

The key advantage of this data is that we can exploit the differential aging of local labor markets over the last 50 years, in order to causally identify the effect of demographic change. We employ an instrumental variables strategy, which uses the fact that current demographic changes are largely determined by the age structure a decade earlier, and that aggregate educational attainment can be used to predict the change at the local labor market level (a shift-share IV). Hence, we can extract plausibly exogenous variation in potential experience using the predicted age structure from earlier years (adjusting for aggregate changes in education). We flexibly capture aggregate changes in labor demand (e.g. technology) that might be experience-biased, in policies or in other factors, by time fixed effects. Changes in these variables that vary across LLM-years are removed by the instrumental variable and any level differences across local labor markets are absorbed by LLM fixed effects.

Our adaptation of the Jeong, Kim, and Manovskii (2015) framework for the employment margin and to the local labor market level prescribes a three-step empirical approach. For each LLM in each year, we run at the individual level wage and employment choice regressions on potential experience, to identify the price and the employment gradient of experience. The second step of our empirical analysis relates these relative wages and employment rates to the relative experienced labor inputs, generated by computing average years of potential experience in the panel of LLMs. Since relative experienced inputs may be driven by demand as well as supply across LLMs, we instrument experience supply using the predicted age structure (adjusted by aggregate changes in education) of the LLM from ten years earlier. This third step of the empirical approach also accounts for measurement error in LLM-year-level experience that is due to sampling variation. We take this approach, rather than an alternative one-step estimation, since it is both transparent and computationally more feasible, as we explain in Section 3.2.

We measure the wage return to experience as the percent increase in wages due to an extra year of an individual's potential experience, and the full-time employment gradient of experience as the percentage point increase in the probability of working full-time. Our estimates at the commuting zone level imply that when the average experience in a local labor market increases by one year, it reduces the wage return from 
1.44 to 1.36 percent (or 1 stdev of average experience changes the return by 0.6 stdev) and the full-time employment gradient from 0.32 to 0.22 percentage points (a 1:1 stdev effect). ${ }^{2}$ Both of these effects are statistically significant, robust to alternative specifications, and in line with our theoretical model. The effect on the full-time employment gradient is a new empirical finding and potentially important, as discussed above. It is also larger in terms of standardized coefficients than the effect on the wage return.

Previous papers studying the effect of demographic change on relative labor market outcomes for workers of a given age or experience have focused on wages. These include Katz and Murphy (1992), Card and Lemieux (2001), Jeong, Kim, and Manovskii (2015), and Caselli (2015), but also early works by Welch (1979) and Freeman (1979) which analyzed the effects of cohort size. In line with this literature, we find that rising relative experience supply leads to falling relative wages of experienced individuals. But we newly establish that it at the same time leads to a falling relative employment and labor force participation rate of this group. We also use a novel identification strategy in this context based on local labor markets in order to disentangle experience supply effects from demand or other potential confounders. Unlike most of the literature, which allocates workers based on their experience into discrete groups, we follow Jeong, Kim, and Manovskii (2015) and treat workers' supply of experience as continuous. As mentioned above, the key advantage of our model is that it yields one price and one gradient of experience, which fully summarize how wages and employment rates vary with individuals' years of experience (see Section 3.2 for details).

The paper continues as follows. The next section presents the economic model and derives implications of demographic change for relative wages and employment rates. Section 3 discusses the data and the empirical strategy. Section 4 presents the main estimation results for relative full-time employment and wages as well as important robustness checks and results for additional employment-related outcomes. Section 5 evaluates the contribution of experience supply to the U.S. aggregate evolution of the price and the employment gradient of experience over the last decades. The final

\footnotetext{
${ }^{2}$ Whereas we are interested in the effect of demographic change, Jeong, Kim, and Manovskii (2015) are studying the effect that actual experience conditional on age has on the price of experience. They find in the regression of the log price of experience on $\log$ average experience (in their notation) a coefficient of $\mu-1=-4.21$. When we run the same regression as they do in our data and with potential experience (i.e. age minus education minus six), we obtain -1.70 (see Section 4.2.1). We do not consider this as our main specification, because it is not implied by the theory for the employment gradient estimations.
} 
section concludes.

\section{Economic Model}

\subsection{Aggregate Level: Production}

Following Jeong, Kim, and Manovskii (2015), our starting point is to assume that production can be described by a CES production function.

$$
Y=A\left(I^{\frac{\varepsilon-1}{\varepsilon}}+\delta E^{\frac{\varepsilon-1}{\varepsilon}}\right)^{\frac{\varepsilon}{\varepsilon-1}}
$$

where $I$ is inexperienced labor and $E$ experienced labor input, $\delta$ relative efficiency of experience (due to experience-augmenting technology), and $A$ a neutral technology parameter augmenting both factors, which reflects both total factor productivity and any other input to production. The parameter $\varepsilon$ is the elasticity of substitution between the two inputs. The marginal products of inexperienced and experienced labor are given by:

$$
\begin{aligned}
M P I & =A\left(I^{\frac{\varepsilon-1}{\varepsilon}}+\delta E^{\frac{\varepsilon-1}{\varepsilon}}\right)^{\frac{1}{\varepsilon-1}} I^{-\frac{1}{\varepsilon}} \\
M P E & =A\left(I^{\frac{\varepsilon-1}{\varepsilon}}+\delta E^{\frac{\varepsilon-1}{\varepsilon}}\right)^{\frac{1}{\varepsilon-1}} \delta E^{-\frac{1}{\varepsilon}}
\end{aligned}
$$

Since competitive firms' cost minimization implies that each type of labor's marginal products are equalized to their factor prices, the experience price is given by

$$
p=\frac{M P E}{M P I}=\delta\left(\frac{E}{I}\right)^{-\frac{1}{\varepsilon}}
$$

which is negatively related to average experience per worker. The relationship between the price of experience and the relative supply is linear in logs

$$
\ln (p)=\ln (\delta)-\frac{1}{\varepsilon} \ln \left(\frac{E}{I}\right) .
$$

We present alternative empirical frameworks, which differ in the specification of $I$, $E$, and thus of $p$. The first specification obtains the return to experience in a reduced 
form linear wage regression and relates it to the average experience in each LLM-year. This modeling strategy is one of the advantages of Jeong, Kim, and Manovskii's paper relative to Katz and Murphy (1992) or Card and Lemieux (2001), as it does not rely on assigning individual workers into discrete skill groups, but uses fine-grained information about workers' relative supply of experience skill. As one of the robustness checks in section 4.2.1, we also show results for a specification that assigns workers into discrete experience groups.

\subsection{Individual Level: Labor Supply}

Our preferred worker-level wage function is inspired by the model of Jeong, Kim, and Manovskii (2015). A worker $j$ supplies units of inexperienced ('raw') labor as well as their experience skill $e_{j}$ (in years of experience). Denoting the price of experience by $p$, workers' potential wages are in $\log s^{3}$

$$
\ln \left(w_{j}\right)=p e_{j}+\alpha_{1}+\beta_{1} x_{j}+u_{j}
$$

where $x_{j}$ is a vector of observable productive characteristics other than experience (such as education, race, gender), for which we control to identify an unconfounded price $p$, and $u_{j}$ is an unobserved individual-specific component.

To model the employment decision, we assume for workers' reservation wages

$$
\ln \left(\underline{w}_{j}\right)=\gamma e_{j}+\alpha_{2}+\beta_{2} x_{j}+v_{j}
$$

which allows for the reservation wage to depend on workers' experience $e_{j}$ (or age conditional on education) and other characteristics $x_{j}$, where the coefficient $\gamma$ could take any sign, as well as an idiosyncratic component $v_{j}$. A worker $j$ participates in the

\footnotetext{
${ }^{3}$ This specification of the wage function is a simplification and approximation of the setup of Jeong, Kim, and Manovskii (2015). There, workers supply both raw labor, earning $w^{I}$ and experience labor, earning $w^{E}$ per unit. This implies

$$
\ln \left(w_{j}\right)=\ln \left(1+p e_{j}\right)+\ln \left(w^{I}\right)+\beta_{1} x_{j}+u_{j}
$$

with $p=\frac{w^{E}}{w^{I}}$ and raw labor normalized to 1 conditional on $x_{j}$, since in our data we cannot distinguish between age and potential experience conditional on education. When approximating $\ln \left(1+p e_{j}\right) \approx p e_{j}$, which is a good approximation if $p$ is small (which we find in our empirical analysis), our specification (5) follows. As a robustness check, we also estimate the "structural" wage Equation (4) in Section 4.2.1.
} 
labor market if $\ln \left(w_{j}\right)>\ln \left(\underline{w}_{j}\right)$ which is equivalent to the following inequality:

$$
\underbrace{\alpha_{1}-\alpha_{2}+\left(\beta_{1}-\beta_{2}\right) x_{j}+\left(u_{j}-v_{j}\right)}_{=z_{j}}>\underbrace{-(p-\gamma) e_{j}}_{\underline{z}\left(e_{j}, p\right)} .
$$

This condition implies that workers participate only if $z_{j}$ (the left hand side), which is the part of the payoff from working that is not due to the worker's experience, exceeds a cutoff that is given by the right hand side. In general, this employment cutoff $\underline{z}\left(e_{j}, p\right)=-(p-\gamma) e_{j}$ depends on a worker's experience $e_{j}$ and the experience price $p$. If $p>\gamma$ (which is an empirical question and is in line with the findings in our data), the cutoff falls in experience, implying that more experienced individuals, conditional on other characteristics $x_{j}$, have a higher employment rate. Note that $\frac{\partial \underline{z}(e, p)}{\partial e}=-(p-\gamma)<0$ if $p>\gamma$, and $\frac{\partial^{2} z(e, p)}{\partial e \partial p}=-1<0$, implying that more experienced workers are impacted more strongly by changes in $p$. This leads to

Proposition 1. The employment cutoff of more experienced workers reacts more strongly to changes in the price of experience.

The employment rate for workers with $e$ experience years and other skills $x$ is given by the fraction of workers whose payoff from working exceeds the employment cutoff and is given by

$$
R(e, p, x)=1-G^{z \mid x}(\underline{z}(e, p)),
$$

where $G^{z \mid x}$ is the cumulative distribution function of $z$ conditional on $x$ and we assume that the idiosyncratic component $u-v$ in the payoff from working is identically distributed across all levels of experience $e$.

Since $\frac{\partial z(e, p)}{\partial p}=-e$, which implies that for $e>0$ the employment cutoff declines in $p$, it follows:

Proposition 2. Conditional on non-experience skills $x$, the employment rate for workers with some experience increases in the price of experience.

To establish how the employment rates change differentially across workers with different years of experiences, we investigate the cross-derivative of (8) with respect to $p$ and $e$. Using Proposition 1 and denoting the density function of $z \mid x$ by $g^{z \mid x}=\frac{\partial G^{z \mid x}}{\partial z}$, 
the properties of the model-implied employment rate are $\frac{\partial R(e, p, x)}{\partial p}=-g^{z \mid x}(\underline{z}(e, p)) \frac{\partial \underline{z}(e, p)}{\partial p}>$ $0, \frac{\partial R(e, p, x)}{\partial e}=-g^{z \mid x}(\underline{z}(e, p)) \frac{\partial \underline{z}(e, p)}{\partial e}>0$ if $p>\gamma$, and the cross-derivative is given by

$$
\frac{\partial^{2} R(e, p, x)}{\partial e \partial p}=-g^{z \mid x}(\underline{z}(e, p)) \frac{\partial^{2} \underline{z}(e, p)}{\partial e \partial p}-\frac{\partial g^{z \mid x}(\underline{z}(e, p))}{\partial z} \frac{\partial \underline{z}(e, p)}{\partial e} \frac{\partial \underline{z}(e, p)}{\partial p}
$$

Given Proposition 1, the first term is positive and is due to the fact that more experienced workers' employment cutoff responds more strongly to changes in the experience price. By itself, this implies that a rise in the price of experience increases the employment rate of experienced by more than of less experienced individuals.

The sign of the second term is in general ambiguous as it depends on the shape of the non-experience skill distribution around this employment cutoff $\left(\frac{\partial g^{z \mid x}(\underline{z}(e, p))}{\partial z}\right)$. How it alters the relative employment rates depends on the masses of individuals that are just marginally not-participating. For sufficiently smooth distributions, this term is very close to zero. In fact, if one assumed a constant density, which is implicitly often done in linear probability models, $\frac{\partial g^{z \mid x}(\underline{z}(e, p))}{\partial z}=0$ and the second term is zero. More generally, if the density of workers who are just indifferent about participating is relatively constant across different experience levels, this term is very small, ${ }^{4}$ such that a higher experience price increase the relative employment of more experienced compared to less experienced workers $\left(\frac{\partial^{2} R(e, p, x)}{\partial e \partial p}>0\right)$. We summarize this finding as

Proposition 3. Under reasonable assumptions on the distribution of non-experience skills, the employment rate of more experienced workers reacts stronger to changes in the experience price than the one of less experienced workers.

We will test this prediction in our empirical analysis. To note is that this proposition also suggests that the relative supply of experienced compared to inexperienced labor depends positively on the experience price. In the next subsection, we discuss

\footnotetext{
${ }^{4}$ While for some classes of distributions, e.g. the Uniform distribution, it is always true that $\frac{\partial^{2} R(e, p, x)}{\partial e \partial p}>0$, for many other distributions it is also highly likely to hold in the empirically relevant range of employment cutoffs. Using the definition $\underline{z}(e, p)=-(p-\gamma) e$ and expressions for its derivatives, (9) can be written as $\frac{\partial^{2} R(e, p, x)}{\partial e \partial p}=g^{z \mid x}(\underline{z}(e, p))\left(1+\frac{\partial g^{z \mid x}(\underline{z}(e, p))}{\partial \underline{z}(e, p)} \frac{\underline{z}(e, p)}{g^{z \mid x}(\underline{z}(e, p))}\right)$. A sufficient condition for $\frac{\partial^{2} R(e, p, x)}{\partial e \partial p}>0$ is therefore $\frac{\partial g^{z \mid x}(\underline{z})}{\partial \underline{z}} \frac{\underline{z}}{g^{z \mid x}(\underline{z})}>-1$, i.e. that the elasticity of the density function is larger than minus one. For the normal distribution, at most points in the distribution this is the case. For instance, for $z \mid x \sim N[0,1], \frac{\partial g^{z \mid x}(\underline{z})}{\partial z} \frac{\underline{z}}{g^{z \mid x}(\underline{z})}=-\underline{z}^{2}$, implying that $\frac{\partial^{2} R(e, p, x)}{\partial e \partial p}>0$ when $-1<\underline{z}<1$ which would be associated with employment rates between 16 and 84 percent (and with a larger variance of $z \mid x$ this range increases further).
} 
how the interaction between this relative supply and the relative demand determine in equilibrium the price of experience and employment, and how this is affected by changing demographics.

\subsection{Equilibrium and Demographic Change}

The relative supply of the experience skill of employed workers is given by

$$
\frac{E}{I}=\frac{\sum_{j} e_{j} \tilde{z}_{j} f_{j}}{\sum_{j} \tilde{z}_{j} f_{j}}
$$

where $f_{j}=\mathbb{1}\left[z_{j}>\underline{z}\left(e_{j}, p\right)\right]$ is an indicator for individual $j$ being employed and $\tilde{z}_{j}$ are some individual-level weights. In our preferred empirical specification, these consist of individuals' observed productive characteristics $\exp \left(\beta_{1} x_{j}\right)$, following Jeong, Kim, and Manovskii (2015). An alternative formulation is to set $\tilde{z}_{j}=1$ such that $\frac{E}{I}$ is the simple average of experience.

To illustrate the equilibrium effects of demographic change, we work with this simpler formulation. In this case the equilibrium relative supply of experience skill is average experience weighted by employment rates $\bar{R}(e, p)=\mathbb{E}_{x}(\mathbb{E}(f \mid e, p, x))$. Assuming only workers with 0 to 45 years of experience participate, it can be written as

$$
\frac{E(p)}{I(p)}=\frac{\sum_{e=0}^{45} n(e) e \bar{R}(e, p)}{\sum_{e=0}^{45} n(e) \bar{R}(e, p)}
$$

where $n(e)$ is the number of individuals with $e$ years of experience.

Potential supply, the supply if everyone participated, is given by $\frac{\tilde{E}}{\tilde{I}}=\frac{\sum_{e=0} n(e) e}{\sum_{e=0} n(e)}$. Demographic changes are shifts in the relative group sizes of individuals with different years of experiences. These changes in potential supply have in equilibrium effects on the experience price and supply. When due to aging the supply of experience increases, the supply curve shifts out, as illustrated in Figure 2. Assuming that the relative supply is upward sloping, this leads in equilibrium to a lower experience price and a reduction in the relative employment of experienced workers, which is a leftward movement along the shifted supply curve.

To see the shift of the supply curve due to demographic change formally, define the actual relative experience supply at price $p$ as $S(p)=\frac{E(p)}{I(p)}=\frac{\sum_{e=0}^{45} n(e) e \bar{R}(e, p)}{\sum_{e=0}^{45} n(e) \bar{R}(e, p)}$ and log- 
Figure 2: Slope of the relative labor supply curve of experience

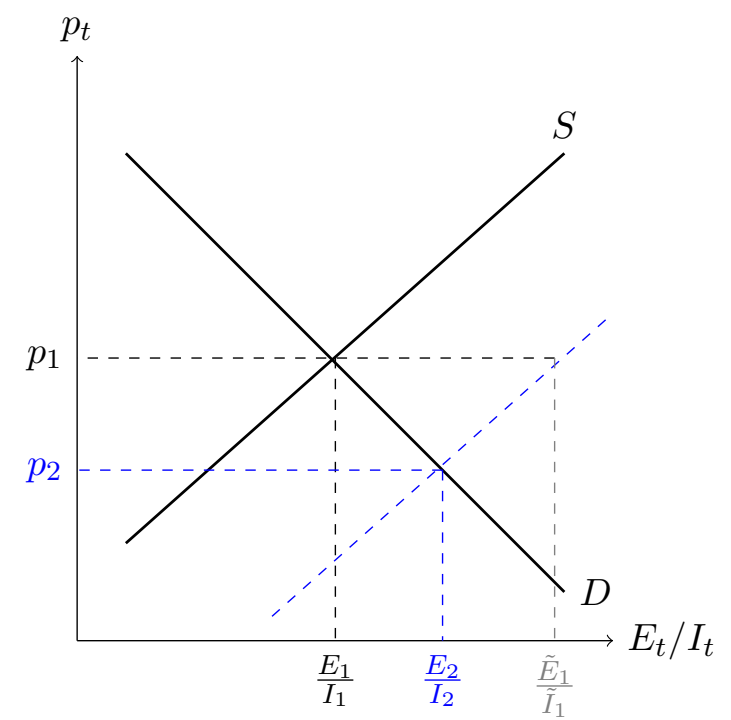

An increase in the experience supply shifts the supply curve to the right (to the dashed line). The resulting fall in the price of experience reduces the quantity along the new supply curve (from $\frac{\tilde{E}_{1}}{\tilde{I}_{1}}$ to $\frac{E_{2}}{I_{2}}$ ), reflecting a reduction in the relative employment rate of more experienced workers.

linearize allowing for changes in the age structure $n(e)$. Holding the price constant, $\widehat{S}=\Delta \ln (S)$, (roughly) the percentage change in potential relative supply, is given by

$$
\widehat{S}=\sum_{e=0}^{45} \underbrace{\left(\frac{n(e) e \bar{R}(e, p)}{E}-\frac{n(e) \bar{R}(e, p)}{I}\right)}_{\Omega(e)} \widehat{n(e)}
$$

where $\widehat{n(e)}=\Delta \ln (n(e))$, (approximately) the percentage change in $n(e)$.

Defining $\Omega(e)=\frac{n(e) e \bar{R}(e, p)}{E}-\frac{n(e) \bar{R}(e, p)}{I}$, it is straightforward that an increase of the number of workers with $\tilde{e}$ years of experience leads to a larger supply at a given price if $\Omega(\tilde{e})>0$, which occurs when $\tilde{e}>\frac{E}{I}$. Hence, when the share of workers with years of experience above the current average increases (which implies that average experience rises), the supply curve shifts to the right. Conversely, when the share of workers with less than the average years of experiences increases, the supply curve shifts to the left.

Market clearing requires that in response to larger supply, the price of experience falls as the demand curve (3) is downward-sloping. A log-linearization gives

$$
\widehat{D}=-\varepsilon \widehat{p}
$$


where $\widehat{D}=\Delta \ln (D)$ and $\widehat{p}=\Delta \ln (p)$.

Log-linearizing of the relative supply (11) allowing for changes in the sizes of demographic groups as well as in the experience price gives

$$
\widehat{S}=\underbrace{\sum_{e=0}^{45} \Omega(e) \widehat{n(e)}}_{\text {potential rel supply change }}+\underbrace{\sum_{e=0}^{45} \Omega(e) \frac{p}{\bar{R}(e, p)} \frac{\partial \bar{R}(e, p)}{\partial p} \widehat{p}}_{\text {rel employment rate change }} .
$$

The first term captures by how much supply changes due to demographic change at a constant price, which is a shift in the supply curve. The second term reflects that induced price adjustments affect employment and thereby the quantity supplied as movements along the supply curve. Under the assumption of $\sum_{e=0}^{45} \Omega(e) \frac{p}{\bar{R}(e, p)} \frac{\partial \bar{R}(e, p)}{\partial p}>0$, the relative supply of experienced labor is upward sloping and, in line with Proposition 3, reflects that experienced workers' employment rates respond stronger than inexperienced workers'. A fall in the experience price then ceteris paribus reduces the relative supply of experience through its effect on employment rates.

In equilibrium, the change in demand has to equal the change in supply, i.e. $\widehat{D}=$ $\widehat{S}$. Following an increase in potential supply due to demographic change, given by $\sum_{e=0}^{45} \Omega(e) \widehat{n(e)}>0$, the market clearing price falls, as

$$
\widehat{p}=-\frac{\sum_{e=0}^{45} \Omega(e) \widehat{n(e)}}{\varepsilon+\sum_{e=0}^{45} \Omega(e) \frac{p}{\bar{R}(e, p)} \frac{\partial \bar{R}(e, p)}{\partial p}}<0
$$

and the equilibrium supply change is

$$
\widehat{S}=\frac{\varepsilon \sum_{e=0}^{45} \Omega(e) \widehat{n(e)}}{\varepsilon+\sum_{e=0}^{45} \Omega(e) \frac{p}{\bar{R}(e, p)} \frac{\partial \bar{R}(e, p)}{\partial p}}
$$

which is $0<\widehat{S}<\sum_{e=0}^{45} \Omega(e) \widehat{n(e)}$. This means that following an increase in potential supply due to aging of the workforce (in Figure 2 the rightward shift in the supply curve), actual supply increases in equilibrium (from $\frac{E_{1}}{I_{1}}$ to $\frac{E_{2}}{I_{2}}$ ), but by less than potential supply since the relative employment rate of more experienced workers falls. This change in employment rates is due to the fall in the experience price (from $p_{1}$ to $p_{2}$ ) and in the figure illustrated as the leftward movement along the new supply curve 
from $\frac{\tilde{E}_{1}}{\tilde{I}_{1}}$ to $\frac{E_{2}}{I_{2}}$.

The equilibrium effects of demographic change are summarized in Proposition 4.

Proposition 4. Assuming an upward sloping supply curve for relative experience, higher potential supply in equilibrium

- decreases the experience price,

- which lowers the relative employment rate of experienced workers,

- and thus increases actual supply by less than 1:1.

\section{Data and Empirical Strategy}

In this section we describe how we apply the model described in the previous section to local labor markets (LLMs). Our starting point is to assume that workers' employment decisions and production occur at the LLM level. In a further application we also explore implications for worker migration across local labor markets.

\subsection{Micro-Level Data}

We use data from the U.S. Census of 1950, 1960, 1970, 1980, 1990, 2000 and the American Community Survey (ACS) of 2010, which we access from IPUMS-USA, provided by Ruggles, Alexander, Genadek, Goeken, Schroeder, and Sobek (2010). ${ }^{5}$

We construct a sample of the working age population 16-65 in the census/ACS years 1960 to 2010. We translate the consistent education variable in the census/ACS into years of schooling in order to compute the number of years of potential labor market experience. ${ }^{6}$ In particular, we define potential experience as an individual's age minus years of schooling minus six. It is censored below at zero and above at 45 years. Following Jeong, Kim, and Manovskii (2015), we construct an indicator that

\footnotetext{
${ }^{5}$ For the censuses of 1950 and 1960 this is the one percent sample, for the 1980, 1990 and 2000 census the five percent samples, and for the 2010 ACS the one percent sample. For the 1970 census we use the two one percent metro samples in our analysis on the commuting zone level and the two state samples in our analysis at the state level. We also checked for the robustness of our results to the Great Recession using the 2007 ACS instead of the 2010 version.

${ }^{6}$ Education codes below grade nine are given in intervals. We code "Nursery up to grade 4 " as three years of schooling and "Grade 5, 6, 7, or 8" as seven years.
} 
divides individuals into "high-school" workers with 12 or less years of schooling and "college" workers with more than 12 years of schooling.

Earnings in the Census are reported for the previous year and in the ACS for the period of the past 12 months. To construct hourly wages, information on hours worked over the same period is needed. However, the availability of hours data differs across census years. In particular, prior to 1980 there is no information on usual hours worked per week, while hours and weeks worked last year are only available as intervals. Similar to Katz and Autor (1999), we therefore restrict attention to wages of only fulltime workers. For these workers we compute an hourly equivalent wage by dividing their salary income by 35 hours and 40 weeks (also see Footnote 8 ). The advantage of this calculation of wages is that it is relatively precise, as it includes only rather similar (full-time) workers and does not introduce noise from additional assumptions about hours and weeks worked. ${ }^{7}$ Accordingly we define an indicator variable for fulltime full-year employment (in non-farm, non-military occupations) in the previous year, based on whether respondents worked at least 40 weeks, 35 hours per week $^{8}$ and had a positive labor income. In our main empirical analysis of section 4.1 we study how wages and full-time employment, as defined here, are affected by demographic change. Alternatively, we can study the effect on the current employment status, e.g. labor force participation, unemployment, etc.; we do this in section 4.3.

Table A2 in the Appendix lists summary statistics for the sample of individuals aged 16-65 that are in our regression sample. The top panel shows the population and the bottom panel full-time workers only. We do include females in our analysis, as their experience supply matters for the general equilibrium effect that we are after, but our main results are robust to excluding females (see Section 4.2.2).

The 1950 census data are not used for our wage and choice regressions, but they

\footnotetext{
${ }^{7}$ The 1960 and 1970 Censuses only provide intervals for weeks worked and no information at all for usual hours in the previous year. An alternative would be to compute wages based on the midpoints of the weeks worked intervals and using hours worked last week as a proxy for hours in the previous year. This alternative definition of wages gives very similar results.

${ }^{8}$ Since usual hours last year is not available prior to the 1980 Census, in earlier years we use an interval of hours worked last week as a proxy. In the 1960 and 1970 Census we also do not know the exact number of weeks worked last year but only an interval. We deem individuals to work full-time if their hours worked were at least in the 35-39 hours bracket and their weeks worked in the 40-47 weeks bracket or higher.
} 
are used to construct our instrument for experience. ${ }^{9}$ This is based on predicting the current age structure of a given local labor market using the censuses ten years earlier. We cannot use the 1960 or 1970 census for the wage regressions either when we do our analysis on the commuting zone (czone) level as opposed to the state level. The reason is that county group information, which is necessary for constructing the Autor and Dorn (2012) commuting zones, is not available in 1960 (so we cannot construct our instrument for 1970). ${ }^{10}$

Therefore, our commuting zone analysis begins in 1980; just when the baby boom cohorts start entering the labor market and pushing down the age of the workforce. The state level analysis begins two decades earlier than that, at a time when the average workforce age was still rising. Appendix Table A2 shows that there are more than ten million individual observations underlying the state level analysis (and more than 4.3 million full-time workers). ${ }^{11}$

\subsection{Empirical Strategy}

The theoretical model's Proposition 4 leads to three empirical predictions that we can examine in the data (now in the order that they will be tested):

Empirical Prediction 1. Demographic change that raises the potential supply of relative experience increases the actually observed supply, but under-proportionally.

Empirical Prediction 2. Higher relative experience supply lowers the relative employment rate of experienced workers.

Empirical Prediction 3. Higher relative experience supply lowers the wage return to experience.

Since these are predictions about market equilibrium outcomes, we use an empirical setup where one can arguably observe sufficiently many such equilibria as well as

\footnotetext{
${ }^{9}$ The weeks worked variable in 1950 has many unexplained missing values. Including or excluding the workers with missing weeks either leads to implausibly high or low average wages.

${ }^{10}$ Several county groups (censuses 1970 and 1980) and public use microdata areas (1990, 2000, and 2010) belong to multiple commuting zones. We use weights ('afactor') available on David Dorn's website to probabilistically assign every individual in those geographic units to the respective czones.

${ }^{11}$ In the commuting zone analysis without the 1960 and 1970 censuses, these numbers are 6.8 million and 3.1 million, respectively.
} 
account for confounding factors. In particular, we examine Predictions 1-3 in local labor markets in the U.S. at a frequency of one decade. We use year and LLM fixed effects in order to control for aggregate differences across time and time-invariant differences across locations in the employment gradient and the wage return to experience. This captures the relative employment rate and the price of experience, respectively. We further use an instrumental variable strategy based on predicting current experience from the age structure ten years earlier in order to isolate the relevant changes in local experience supply.

Our empirical analysis consists of three steps. The first step are individual-level employment choice and Mincer wage regressions within each LLM-year of the form: ${ }^{12}$

$$
\begin{gathered}
f_{j l t}=\alpha_{j l t}^{r}+r_{l t} e_{j l t}+\beta_{l t}^{r} x_{j l t}+u_{j l t}^{r} \\
\ln \left(w_{j l t}\right)=\alpha_{j l t}^{p}+p_{l t} e_{j l t}+\beta_{l t}^{p} x_{j l t}+u_{j l t}^{p},
\end{gathered}
$$

where $l$ now indexes the local labor market and $t$ time, $f_{j l t}$ is an indicator for being employed full-time, and $w_{j l t}$ the individual's full-time wage. The wage regression (15) corresponds to Equation (5) from theory and the choice regression (14) is Equation (7) implemented with a linear probability model (probit or logit specifications give similar results). The main regressor of interest is potential experience $e_{j l t}$. As in the theoretical exposition of section 2.2, we include $x_{j l t}$ to control for other factors (non-experience skills) that differ by experience and may influence full-time employment or wages to obtain these relationships cleaned of observable confounders. In line with the recent paper by Jeong, Kim, and Manovskii (2015), we include years of schooling interacted with the college indicator, sex, and race. $u_{j l t}^{r}$ and $u_{j l t}^{p}$ are the regression errors, that is, the individual-specific deviations from their conditional means. ${ }^{13}$

We interpret the coefficient $r_{l t}$ as the experience-employment gradient and $p_{l t}$ as the wage return to experience that prevail in local labor market $l$ in time $t$. The $r_{l t}$-gradient

\footnotetext{
${ }^{12}$ At the commuting zone level, there are 722 LLMs per year in 1980-2010. Therefore, we run 2,888 separate regressions (14) and (15) each (2,888 czone-year observations overall). There are 50 states plus the District of Columbia per year in 1960-2010. However, since Alaska and Hawaii only became states in 1959, our IV estimates have 49 states for the year 1960 (304 state-year observations overall).

${ }^{13}$ Compared to simply computing average wages for experienced and inexperienced workers (e.g. Caselli, 2015), employing the individual-level wage Equation (15) has the advantage that via the control variables $\beta_{l t}^{p} x_{j l t}$ one can remove the confounding effects of other productive characteristics that potentially differ between experienced and inexperienced workers.
} 
corresponds to the term $p-\gamma$ in Equation (7) and captures by how much the full-time employment rate varies with experience, in particular by how much an individual's probability of full-time employment increases with an extra year of experience. The wage return to experience corresponds to $p$ in Equation (5) and captures by how much log wages change with years of experience (measured in log points).

A key strength of the empirical formulation in (14) and (15) is that it results (for each LLM-year) in one estimated gradient and one return that describe how employment and wages vary across workers with different experience. This allows us to construct a panel of gradients and returns, which we can then use to study the effects of demographic change on market-wide relative employment rates and wages. To make this feasible, we rely in the specification of Regressions (14) and (15) on the linearity in $e_{j l t}$. In our main specification $e_{j l t}$ is simply a worker's years of potential experience. In a robustness check we change this into a dummy specification where workers are classified as experienced $\left(e_{j l t} \geq 20\right)$ or inexperienced $\left(e_{j l t}<20\right)$, similar to Card and Lemieux (2001); Caselli (2015). However, our preferred setup is the one linear in potential experience, following Jeong, Kim, and Manovskii (2015), as it uses fine-grained 'within-group' variation in workers' experience. ${ }^{14}$

Estimating Equations (14) and (15) in each LLM-year gives us a panel of local experience-employment gradients and of wage returns to experience. Finally, we also construct a panel of local supplies of experience by computing Equation (10), $\frac{E_{l t}}{I_{l t}}=$ $\frac{\sum_{j \in\{l, t\}} e_{j l t} \tilde{z}_{j l t} f_{j l t}}{\sum_{j \in\{l, t\}} \tilde{z}_{j l t} f_{j l t}}$, with observed individual productivity weights $\tilde{z}_{j l t}=\beta_{l t}^{p} x_{j l t}$ following Jeong, Kim, and Manovskii (2015). ${ }^{15}$

In the second step of our empirical analysis, we relate the experience-employment gradient and the wage return to experience to the relative supply of experience $\frac{E_{l t}}{I_{l t}}$ in

\footnotetext{
${ }^{14}$ Notice that choice estimation of Equation (14) is more general than our economic model. It summarizes the empirical relationship between experience supply and experienced workers' employment, whether this is mediated via the price of experience in a competitive factor market or whether there are some rigidities and firms are for example unwilling to hire or retain experienced workers at the going wage rate. Our empirical findings below support the competitive model of Section 2, as we find no effect on unemployment, a strong effect on labor force participation, and a substantial effect on the wage return to experience.

${ }^{15}$ Not weighting by individual productivity (i.e. setting $\tilde{z}_{j l t}=1$ ) gives similar results.
} 
our panel of local labor markets: ${ }^{16}$

$$
\text { outcome }_{l t}=\eta\left(\frac{E_{l t}}{I_{l t}}\right)+D_{l}+D_{t}+\text { error }_{l t},
$$

where outcome $e_{l t}$ is either $r_{l t}$ or $p_{l t}$, estimated in the first step. For the regression we use the average experience of actual full-time employment, and not of the working age population, because in the economic model this determines the relative marginal product and thus the market price of experience. We also explore a log-log version of Equation (16), which is closer to the classic Katz and Murphy (1992) regression and for the wage return to experience corresponds to the theoretical relationship (3). The fixed effects $D_{l}$ flexibly control for time-invariant differences in relative full-time employment or wages of experienced workers across locations, while the $D_{t} \mathrm{~s}$ control for aggregate changes in these variables over time (e.g. due to experience-biased changes in labor demand or trends in early retirement behavior which might be due to policies).

However, it is likely that changes in the demand for experience exist which vary across LLM-years. For example, in one local labor market the demand for experienced workers might increase, leading through market adjustments also to an increase in (local) experience supply (e.g. via changes in participation or migration). Therefore, in the third step of the analysis we address this potential endogeneity problem and design an empirical strategy to disentangle changes in local supply of experience from changes in demand or other factors. Our approach is based on the predicted (in the absence of local shocks) supply of experience in each LLM-year. As we are exploiting in our fixed effect regression (16) the variation across local labor markets, what is needed is to project the differential supplies of potential experience across LLMs and years. This prediction is first and foremost based on the age structure (by year and LLM), which is predetermined and observed in the previous census. Since we want to project the supply of potential experience, we refine the prediction from aging with changes in years of education in the aggregate data (by year, age and gender).

Specifically, we want to predict the supply of experience per worker aged 16 to 65 in LLM $l$ and year $t$. To do this we use the micro data on all individuals observed

\footnotetext{
${ }^{16}$ Observations in micro-level regressions (14) and (15) are weighted by the individual workers' sampling weights. Observations in Regression (16) are weighted by the relative size (share of summed individual weights) of the LLM in the respective preceding census.
} 
in the previous decennial census, i.e. in $t-10$, where the relevant age groups are the 6 to 55 year old, as these individuals will form the working-age population in $t$ if they do not migrate (e.g. due to local shocks). We project their potential experience for year $t$ after they would have aged by ten years and would have acquired education according to the age- and gender-specific national education attainment rates in $t$. We then aggregate to obtain the LLM's predicted experience supply in $t$. These steps can be summarized by the following equation describing the construction of the predicted supply of experience per worker in LLM $l$ and year $t$ :

$$
\left(\frac{E_{l t}}{I_{l t}}\right)^{I V}=\frac{1}{\sum_{j} \omega_{j l t-10}} \sum_{j} \omega_{j l t-10}\left[\left(a g e_{j l t-10}+10\right)-\widehat{e d u c_{j t}}-6\right]
$$

for all $j$ observed in $l$ at $t-10$ with $6 \leq a g e_{j l t-10} \leq 55$,

where $\omega_{j l t}$ denote individual level sampling weights, $a g e_{j l t}$ the age of individual $j$ in LLM $l$ and year $t$, and $\widehat{e d u c_{j t}}$ is the educational attainment predicted from national rates for $j$ in year $t$ given their gender and age. As the construction of the instrument $\left(\frac{E_{l t}}{I_{l t}}\right)^{I V}$ is based on the micro data, it makes use of the entire distribution of (in 10 years' time working-age) individuals' age. In practice, if a local labor market has many young individuals in $t-10$, of whom some may not have entered the labor market yet, it is predicted to exhibit relatively low experience supply in $t$; vice versa, an LLM with many middle-aged and older individuals up to age 55 in $t-10$ is predicted to have a relatively high experience supply in $t$.

We employ our three-step approach for its transparency as well as computational reasons. The alternative of estimating the model in a more direct way, constructing the instrument first and then estimating the model in one step, would be very demanding in our context. It would entail regressions of the micro-level employment choice (14) and wage (15) equations directly onto individuals' experience interacted with LLMlevel experience supply, instrumented by individuals' experience interacted with predicted LLM experience supply, as well as on a set of individual-level controls and LLM and time fixed effects. This by itself would be computationally demanding given the large number of observations and commuting zone-years. Moreover, the correct specification using individual productivity weights to construct the LLM experience 
supply (e.g. see Equation (10)) would require such an estimation to be either iterative or to be non-linear, yet large-scale. In contrast, our three-step approach is easy to understand and implement. It also provides intermediate LLM-level panel data that can be checked for plausibility (Tables 1 and A11) and is transparent in that sense as well.

Our instrument is exogenous if, controlling for permanent differences across LLMs $D_{l}$ and aggregate differences across years $D_{t}$, the age structure in a given LLM in $t-10$ is not affected by the relative demand for experience in $t$. If it were to some extent affected by the demand for experience in $t$, our instrument would not fully succeed in extracting variations in experience at the LLM level that are due to changes in supply. In this case, we would expect $\eta$ from Equation (16) to be over-estimated (underestimated in absolute value), as demand shocks work in the opposite direction of the predicted negative relationship of experience supply with $r_{l t}$ and $p_{l t}$. As a robustness check in section 4.2.1, we also estimate the model in first differences where the instrumental variable is the change in predicted experience supply constructed from the censuses in $t-10$ and $t-20 .{ }^{17}$

For validity of the instrument, we further need that a first stage exists and that the exclusion restriction holds. The first stage coincides with a test of Empirical Prediction 1 , as it is the regression of actual experience supply on our instrument of potential supply. ${ }^{18}$ The exclusion restriction states that the age structure in $t-10$ does not affect the relative employment or price of experience in $t$ other than through its effect on the supply of experience in $t$. As one of our main specifications, we therefore control for average education in the IV estimation, since changes in a local labor market's age structure may come with changes in educational attainment. In robustness checks, we further include additional demographic characteristics of the LLM as well as the employment structure in terms of (broad) industries and occupations. We also estimate Equation (16) separately for college and high-school workers (Section 4.2.2), as the perfect substitutability between education groups implied in our model requires the

\footnotetext{
${ }^{17}$ The first differences specification is similar to Maestas, Mullen, and Powell (2016) who estimate the effect of aging on absolute outcomes, such as GDP per capita and total labor supply at the U.S. state level.

${ }^{18}$ Admittedly, this estimation may be downward-biased due to measurement error in potential supply. Therefore, our main test in the paper is the direct effect on relative participation rates (i.e. the instrumented Equation (16) for the employment gradient), implied by Empirical Prediction 2, which constitute the difference between actual experience of workers and actual experience of the population that underlies Empirical Prediction 1.
} 
results to hold up for both of them.

Assuming that our empirical identification strategy is valid, it provides identification of the price elasticity of demand and of workers' employment response in what may be interpreted as a simultaneous equations model of the market for experience skill. This reasoning is illustrated in Figure 2: demographic change shifts the relative supply of experience to the right. While the previous literature assumed that labor supply by experience is inelastic (the relative employment rate of experienced workers is unaffected by their relative abundance) and thus vertical, our empirical results below show that it is indeed upward-sloping as sketched in the figure. ${ }^{19}$ Therefore, as derived in Section 2.3 and summarized in Proposition 4, the actual input of experienced workers rises by less than the shift in the supply curve $\left(\frac{E_{l 2}}{I_{l 2}}\right.$ instead of $\left.\frac{\tilde{E}_{l 2}}{\tilde{I}_{l 2}}\right)$ and also the effect on the new equilibrium price $p_{2}$ is weaker. Demographic change hence may have general equilibrium participation effects that attenuate the overall effect on employment and affect individuals' lives beyond declining wage rates.

Figure 3: Relative experience supply shock in LLM 1 with migration response

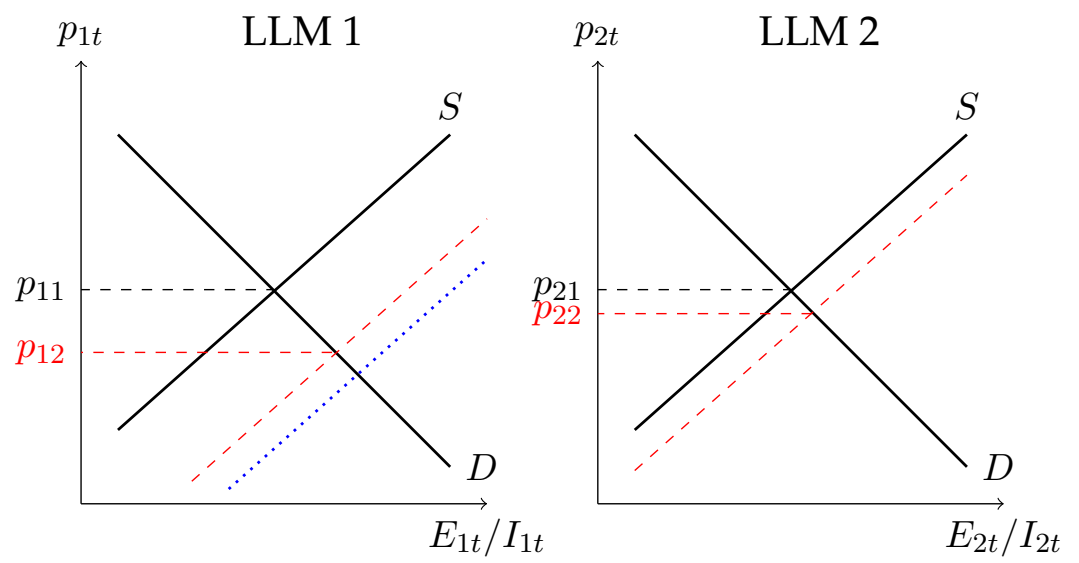

Finally, note that our identification strategy is robust to an employment response that runs in a third dimension of the demand and supply diagram. Figure 3 illustrates an endogenous migration response of rising relative migration of experienced workers from LLM 1, which was hit by an aging shock, to LLM 2. The original shock in LLM 1 moves the relative supply of experience down to the dotted line, which goes in hand

\footnotetext{
${ }^{19} \mathrm{We}$ do not focus on the intensive margin of labor supply as censuses prior to 1980 did not include detailed information on hours worked, but only brackets. We also find strong effects on the extensive margin.
} 
with a substantial decline in the relative price of experience. In response, some relatively experienced individuals may decide to move to LLM 2, increasing the supply of experience there and reducing it in LLM 1 . Nonetheless, if the dashed line shifts further out in LLM 1 than LLM 2 (which is supported by the IV first-stage results below), our empirical strategy identifies the slope of the demand curve from that difference. As long as it does not perfectly smoothen out all of the original change in experience supply, endogenous migration is therefore not a concern, but an additional outcome of interest. In fact, in Section 4.3 we find rather weak evidence for a negative effect of rising experience on the in-migration of experienced workers.

\subsection{Variation in the Local Labor Market-Year Panel}

Figure $\mathrm{A} 1$ in the appendix plots the variation in average age of full-time workers across commuting zones of the contiguous U.S. for the years 1970, 1990, and 2010, which constitute the peaks and the trough of the age and experience cycle in our sample (see Figure 1). ${ }^{20}$ The fixed effects in our second-stage regression (16) remove time-invariant differences across LLMs and aggregate changes over time, which admittedly makes up a large part (90-95 percent) of the variation in age and potential experience in the czone and the state panel. Nonetheless, one can also visually infer from the figure that substantial differences in aging remain which run across LLM-years and which are particularly informative for identification.

The top panel of Table 1 reports the results collected from the individual-level regressions as well as other information for our LLM-year panel at the czone level. For each year, the table reports mean and standard deviations of the variation across LLMs for the variables named in the top row. Column 1 shows the experience gradient of full-time employment (multiplied by 100), obtained from estimating (14), and column 2 the wage return to experience (times 100) from (15). The last three columns show for full-time workers statistics on the supply of experience (as computed in Section 3.2), years of education, and the share of females.

The bottom panel of Table 1 shows the corresponding information for the state panel starting in 1960. The means are very similar, but the standard deviations (es-

\footnotetext{
${ }^{20}$ The borders drawn into Figure A1 are for counties in 1990, which is a finer categorization than czones, but the age variation colored into the map is across the 722 czones.
} 
Table 1: Descriptive Statistics for the Commuting Zone and State Panels

\begin{tabular}{lcccccc}
\hline \hline & Fgrad x100 & Rtrn x100 & Expr Suply & Avg Age & Yrs Educ & Female \\
\hline $\begin{array}{l}\text { Czone Panel } \\
\begin{array}{l}1980 \\
\text { mean }\end{array}\end{array}$ & & & & & & \\
sd & 0.37 & 1.28 & 18.6 & 37.9 & 12.4 & 0.38 \\
\hline 1990 & 0.14 & 0.21 & 1.0 & 1.0 & 0.4 & 0.03 \\
mean & 0.28 & 1.49 & 18.5 & 38.2 & 13.0 & 0.42 \\
sd & 0.16 & 0.24 & 0.8 & 0.7 & 0.4 & 0.03 \\
\hline 2000 & & & & & & \\
mean & 0.28 & 1.44 & 20.0 & 39.8 & 13.2 & 0.43 \\
sd & 0.15 & 0.20 & 0.8 & 0.7 & 0.4 & 0.02 \\
\hline 2010 & & & & & & \\
mean & 0.34 & 1.50 & 21.6 & 41.9 & 13.5 & 0.46 \\
sd & 0.12 & 0.20 & 1.1 & 0.9 & 0.4 & 0.02 \\
\hline Total & & & & & & \\
mean & 0.32 & 1.44 & 19.8 & 39.7 & 13.1 & 0.43 \\
sd & 0.15 & 0.23 & 1.6 & 1.8 & 0.5 & 0.04 \\
\hline$N$ & 2888 & & & & &
\end{tabular}

State Panel

\begin{tabular}{lcccccc}
\hline 1960 & & & & & & \\
mean & 0.45 & 0.88 & 22.0 & 40.1 & 10.7 & 0.27 \\
sd & 0.08 & 0.14 & 0.7 & 0.8 & 0.5 & 0.03 \\
\hline 1970 & & & & & & \\
mean & 0.59 & 0.97 & 21.4 & 40.1 & 11.5 & 0.31 \\
sd & 0.08 & 0.13 & 0.7 & 0.7 & 0.4 & 0.02 \\
\hline 1980 & & & & & & \\
mean & 0.38 & 1.29 & 18.5 & 37.9 & 12.5 & 0.38 \\
sd & 0.11 & 0.13 & 0.8 & 0.9 & 0.3 & 0.02 \\
\hline 1990 & & & & & & \\
mean & 0.28 & 1.49 & 18.4 & 38.2 & 13.1 & 0.42 \\
sd & 0.10 & 0.16 & 0.4 & 0.5 & 0.2 & 0.02 \\
\hline 2000 & & & & & & \\
mean & 0.29 & 1.42 & 20.0 & 39.8 & 13.2 & 0.43 \\
sd & 0.09 & 0.11 & 0.5 & 0.5 & 0.2 & 0.02 \\
\hline 2010 & & & & & & \\
mean & 0.35 & 1.48 & 21.5 & 41.8 & 13.6 & 0.46 \\
sd & 0.07 & 0.12 & 0.6 & 0.6 & 0.2 & 0.02 \\
\hline Total & & & & & & \\
mean & 0.37 & 1.30 & 20.2 & 39.8 & 12.6 & 0.39 \\
sd & 0.13 & 0.27 & 1.5 & 1.5 & 1.0 & 0.07 \\
\hline$N$ & 304 & & & & & \\
\hline \hline
\end{tabular}

For each year, the table shows local labor market means and standard deviations of the variables named in the top row. The first and second columns are the full-time gradient $r_{l t}$ and the return to experience $p_{l t}$ from regressions (14) and (15), respectively. Column 3 shows the supply of experience, 4 years of education and 5 the share of females among full-time workers. The top half of the table shows the descriptive statistics for the commuting zone panel, the bottom for the state panel. 
pecially within year) are unsurprisingly smaller. Overall there are 2,888 observations in the czone panel and 304 observations in the state panel. The means in the tables reveal that over 1980-2010 the full-time employment gradient first dropped and then recovered, the wage return to experience increased, and the experience supply first decreased over 1970-1990 (due to baby boomers entering the labor market) and then increased quite considerably (due to aging).

The differences in the age and thus in the experience structure across local labor markets and over time originate from a variety of sources. As documented by Jones and Tertilt (2008), rural and urban areas not only had historically different fertility rates, but also underwent the fertility transition at different times and speeds, which to some degree was accompanied by migration from rural to urban areas. The differential changes in family sizes went to a certain extent in hand with variation in birth control and abortion legislation as well as in anti-obscenity laws, which persisted in some areas until the mid-1960s (see Bailey, 2010). These differences in birth and migration rates, and additionally in mortality rates, have very persistent effects on the age structure, potentially even across multiple generations, which is also stressed by Bronson and Mazzocco (2016). The regional variation in the population's age composition feeds on to variation in the experience supply, which is what we exploit in our empirical analysis as described above.

\section{The Effect of Demographic Change on Relative Em- ployment Rates and Wages}

In this section we estimate the effect of demographic change on the experience-gradient for full-time employment and on the return to experience in full-time workers' wages. Our baseline results are for commuting zones (czones) as the local labor market level, but we also report results at the state level as a comparison and robustness check. We then show important alternative specifications and subsamples as further robustness checks as well as results for additional employment-related outcomes. 


\subsection{Estimation Results}

As described in Section 3.2, after constructing the local labor market-year panel we estimate (16) for the outcomes of interest, the full-time employment gradient $\left(r_{l t}\right)$ and the return to experience in full-time workers' wages $\left(p_{l t}\right)$.

Table 2 reports the relationship of the supply of experience with the relative fulltime employment rate (top segment) and relative wages of experienced workers (bottom segment) when the LLM-year panel regression (16) is estimated by OLS. The first column of the table's top segment shows that average potential experience and the fulltime gradient with respect to potential experience covary positively across the panel of commuting zones. This relationship does not change when we control in column (2) for average years of education, which might differ with workforce age. ${ }^{21}$ The log$\log$ specification of column (3) indicates a (qualitatively) similar relationship, although the interpretation changes to an elasticity and we lose some observations because the estimated full-time employment gradient is not positive in all czone-years. Columns (4) to (6) conduct the corresponding analysis for states as LLMs. In the OLS estimates, there is no systematic relationship between experience supply and the full-time employment gradient detectable on this level.

The bottom segment of Table 2 shows the return to experience according to fulltime workers' wages. Contrary to the employment-experience gradient, the return to experience is negatively correlated with average potential experience across LLMyears in columns (1)-(3) and (4)-(6). The messages the two segments of Table 2 give about the relationship between supply of experience and labor market opportunities of experienced workers is mixed. This is not surprising, because in the OLS it is not clear whether changes in the experiencedness of LLMs occur because of shocks to supply or demand for such workers. We therefore use in the following the instrumental variables strategy we proposed in Section (3.2), in order to isolate variation in experience that is solely due to supply.

The top segment of Table 3 reports the first stage from this IV regression. In line with Empirical Prediction 1, the coefficients of actual on predicted experience from the census ten years earlier are positive but smaller than one. For example, in column

\footnotetext{
${ }^{21}$ More educated czone-years have lower relative full-time employment rates of experienced workers in column (2). For the state level this relationship is not as clear (column (6)).
} 
Table 2: Full-Time Employment Gradient and Wage Return to Experience (OLS)

\begin{tabular}{|c|c|c|c|c|c|c|}
\hline Full-time Empl & $\begin{array}{c}(1) \\
\text { Fgrad } \times 100\end{array}$ & $\begin{array}{c}(2) \\
\text { Fgrad x100 }\end{array}$ & $\begin{array}{c}(3) \\
\text { Ln(Fgrad) }\end{array}$ & $\begin{array}{c}(4) \\
\text { Fgrad x100 }\end{array}$ & $\begin{array}{c}(5) \\
\text { Fgrad x100 }\end{array}$ & $\begin{array}{c}(6) \\
\operatorname{Ln}(\text { Fgrad })\end{array}$ \\
\hline Avg Experience & $\begin{array}{c}0.05^{* * *} \\
(0.01)\end{array}$ & $\begin{array}{c}0.05^{* * *} \\
(0.01)\end{array}$ & & $\begin{array}{c}0.01 \\
(0.01)\end{array}$ & $\begin{array}{c}0.01 \\
(0.01)\end{array}$ & \\
\hline Yrs Education & & $\begin{array}{c}-0.12^{* * *} \\
(0.03)\end{array}$ & & & $\begin{array}{l}-0.01 \\
(0.02)\end{array}$ & \\
\hline Ln(Avg Exper) & & & $\begin{array}{c}3.05^{* * *} \\
(0.73)\end{array}$ & & & $\begin{array}{c}0.63 \\
(0.73)\end{array}$ \\
\hline Wages & Rtrn x100 & Rtrn x100 & Ln(Rtrn) & Rtrn x100 & Rtrn x100 & Ln(Rtrn) \\
\hline Avg Experience & $\begin{array}{c}-0.04^{* * *} \\
(0.01)\end{array}$ & $\begin{array}{c}-0.03^{* *} \\
(0.01)\end{array}$ & & $\begin{array}{l}-0.03 \\
(0.02)\end{array}$ & $\begin{array}{l}-0.03 \\
(0.02)\end{array}$ & \\
\hline Yrs Education & & $\begin{array}{l}0.13^{* * *} \\
(0.04)\end{array}$ & & & $\begin{array}{c}0.01 \\
(0.03)\end{array}$ & \\
\hline Ln(Avg Exper) & & & $\begin{array}{c}-0.51^{* * *} \\
(0.19)\end{array}$ & & & $\begin{array}{c}-0.32 \\
(0.33)\end{array}$ \\
\hline Obs (Fullt Emp) & 2888 & 2888 & 2632 & 304 & 304 & 303 \\
\hline Obs (Wages) & 2888 & 2888 & 2888 & 304 & 304 & 304 \\
\hline Fixed Effects & czone+year & czone+year & czone+year & state+year & state+year & state+year \\
\hline Sample & $\geq 1980$ & $\geq 1980$ & $\geq 1980$ & $\geq 1960$ & $\geq 1960$ & $\geq 1960$ \\
\hline
\end{tabular}

The table reports results from the second-stage estimation (16) using OLS. Dependent and independent variables are constructed from regressions (14) and (15) in each LLM-year using an individual's full-time employment dummy (top segment) and wage (bottom segment) as the dependent variable. Columns (1) to (3) show estimates for the panel of commuting zones over 1980-2010, columns (4) to (6) for states over 1960-2010. Robust standard errors in parentheses are clustered on state: ${ }^{*} \mathrm{p}<0.1,{ }^{* *}$ $\mathrm{p}<0.05,{ }^{* * *} \mathrm{p}<0.01$.

(1), a one year predicted increase in experience according to the previous census and the aggregate change in education (see Equation (17)) leads to a 0.48 years increase in actual experience. This is consistent with experience supply having a negative effect on experienced workers' relative employment rates as in theoretical Proposition 4. However, it is also consistent with our identification strategy being successful in removing changes in experience across LLMs that are due to other reasons than supply (such as changes in demand). ${ }^{22}$ For this reason, we directly examine the effect of experience supply on the employment decision by studying below the effect on the full-time gradient with respect to experience.

\footnotetext{
${ }^{22}$ The identification strategy also corrects for measurement error due to sampling variation. Since our census data are subsamples of the population, the supply of experience variables that we compute on the detailed LLM level may be measured with error. However, because the instrument is constructed from an earlier cross-section, the measurement errors in the regressor and IV are uncorrelated. This removes potential attenuation bias in our estimates. Finally, an additional reason why we expect the firststage coefficients to be below one, are endogenous migration decisions. In fact, we find weak evidence below that there is a negative effect of rising experience in an LLM on the in-migration of experienced versus inexperienced workers.
} 
The regression coefficients in the top segment of Table 3 are also highly statistically significant, even conditional on LLM and year fixed effects. The corresponding F-statistics for the first-stage, which can be calculated as the squared t-statistic in our single instrument case, are around 9-15 in the different czones specifications and even considerably higher at the state level. This underlines the relevancy of our instrument. Following the papers by Autor, Dorn and coauthors that study outcomes at the commuting zone level, we cluster standard errors at the state level throughout the analysis. ${ }^{23}$ This allows for correlations within LLMs over time as well as for spatial correlation across commuting zones (Autor, Dorn, and Hanson, 2013). ${ }^{24}$ In Section 4.2.1 below, we conduct a series of robustness checks, including one where we directly control for state interacted with year fixed effects in the commuting zone regressions. Overall, the regression results reported in the top segment of Table 3 therefore support Empirical Prediction 1 in our data; higher (potential) experience supply leads to an increase in the observed experience, but by less than one-to-one.

The middle segment of Table 3 reports the IV second stage result of the effect of experience supply on the relative full-time employment rates of experienced workers, as described by the gradient of full-time work with respect to experience. Recall that this gradient measures by how much one extra year of experience increases the probability that an individual works full-time (and full-year). As one would expect when the variation that is due to demand changes is removed by the instrument, all the relationships from the OLS become smaller and in fact even turn around to become negative. The relationship between actual potential experience and the experience gradient of fulltime employment is now strongly negative and statistically significant throughout. For example, column one implies that an increase in a local labor market's average experience by one year ( $5 / 8$ of a standard deviation of 1.6 according to descriptive Table 1 ) leads to a 0.1 percentage point (the $y$-variable is in $100 \times$ the outcome) lower full-time experience gradient in that LLM (a roughly 30 percent decline from the average of 0.32

\footnotetext{
${ }^{23}$ To take account of the multi-step estimation procedure, we have also bootstrapped the standard errors of the micro-level employment gradients and wage returns together with the IV estimation in the panel of LLM-years for Tables 2-4 using 199 replications. This actually resulted in slightly lower standard errors. We like to err on the conservative side and therefore report the analytical clustered standard errors in the paper.

${ }^{24}$ If they cross state boundaries, commuting zones are assigned to the state with the highest share of employment for the clustering.
} 
Table 3: Full-Time Employment Gradient and Wage Return to Experience (IV)

\begin{tabular}{|c|c|c|c|c|c|c|}
\hline First Stage & $\begin{array}{c}(1) \\
\text { Expernce }\end{array}$ & $\begin{array}{c}(2) \\
\text { Expernce }\end{array}$ & $\begin{array}{c}(3) \\
\operatorname{Ln}(\text { Exper })\end{array}$ & $\begin{array}{c}(4) \\
\text { Expernce }\end{array}$ & $\begin{array}{c}(5) \\
\text { Expernce }\end{array}$ & $\begin{array}{c}\text { (6) } \\
\operatorname{Ln}(\text { Exper) }\end{array}$ \\
\hline Pred Expernce & $\begin{array}{c}0.48^{* * *} \\
(0.15)\end{array}$ & $\begin{array}{c}0.57^{* * *} \\
(0.15)\end{array}$ & & $\begin{array}{c}0.51^{* * *} \\
(0.10)\end{array}$ & $\begin{array}{c}0.65^{* * *} \\
(0.06)\end{array}$ & \\
\hline Yrs Education & & $\begin{array}{l}-1.03^{* * *} \\
(0.23)\end{array}$ & & & $\begin{array}{l}-0.82^{* * *} \\
(0.12)\end{array}$ & \\
\hline Ln(Pred Exper) & & & $\begin{array}{c}0.49^{* * *} \\
(0.16)\end{array}$ & & & $\begin{array}{l}0.53^{* * *} \\
(0.11)\end{array}$ \\
\hline Full-time Empl & Fgrad x100 & Fgrad x100 & Ln(Fgrad) & Fgrad x100 & Fgrad x100 & Ln(Fgrad) \\
\hline Avg Experience & $\begin{array}{c}-0.10^{* *} \\
(0.04)\end{array}$ & $\begin{array}{c}-0.06^{* *} \\
(0.03)\end{array}$ & & $\begin{array}{c}-0.06^{* * *} \\
(0.02)\end{array}$ & $\begin{array}{c}-0.05^{* *} \\
(0.02)\end{array}$ & \\
\hline Yrs Education & & $\begin{array}{l}-0.19^{* * *} \\
(0.03)\end{array}$ & & & $\begin{array}{c}-0.03 \\
(0.02)\end{array}$ & \\
\hline Ln(Avg Exper) & & & $\begin{array}{l}-8.50^{* *} \\
(3.80)\end{array}$ & & & $\begin{array}{l}-4.31^{* * *} \\
(1.10)\end{array}$ \\
\hline Wages & Rtrn x100 & Rtrn x100 & Ln(Rtrn) & Rtrn x100 & Rtrn x100 & Ln(Rtrn) \\
\hline Avg Experience & $\begin{array}{c}-0.08^{* * *} \\
(0.03)\end{array}$ & $\begin{array}{c}-0.10^{* * *} \\
(0.03)\end{array}$ & & $\begin{array}{l}-0.05 \\
(0.04)\end{array}$ & $\begin{array}{l}-0.06 \\
(0.03)\end{array}$ & \\
\hline Yrs Education & & $\begin{array}{l}0.08^{*} \\
(0.05)\end{array}$ & & & $\begin{array}{c}0.01 \\
(0.03)\end{array}$ & \\
\hline Ln(Avg Exper) & & & $\begin{array}{l}-1.28^{* * *} \\
(0.45)\end{array}$ & & & $\begin{array}{l}-0.62 \\
(0.70)\end{array}$ \\
\hline Obs (Fullt Emp) & 2888 & 2888 & 2632 & 304 & 304 & 303 \\
\hline Obs (F-S\&Wage) & 2888 & 2888 & 2888 & 304 & 304 & 304 \\
\hline$R^{2}$ (First Stage) & 0.91 & 0.92 & 0.91 & 0.96 & 0.96 & 0.96 \\
\hline $\begin{array}{l}\text { Fixed Effects } \\
\text { Sample }\end{array}$ & $\begin{array}{l}\text { czone+year } \\
\geq 1980\end{array}$ & $\begin{array}{l}\text { czone+year } \\
\geq 1980\end{array}$ & $\begin{array}{l}\text { czone+year } \\
\geq 1980\end{array}$ & $\begin{array}{l}\text { state+year } \\
\geq 1960\end{array}$ & $\begin{array}{l}\text { state+year } \\
\geq 1960\end{array}$ & $\begin{array}{c}\text { state+year } \\
\quad \geq 1960\end{array}$ \\
\hline
\end{tabular}

The top segment of the table reports the regression of full-time workers' average experience onto its own prediction from the census 10 years prior (first-stage of the IV). The middle and bottom segments display the second-stage estimates (16) for the full-time employment gradient and the wage return to experience, respectively. Columns (1) to (3) show estimates for the panel of commuting zones over 19802010, columns (4) to (6) for states over 1960-2010. Robust standard errors in parentheses are clustered on state: ${ }^{*}<<0.1,{ }^{* *} \mathrm{p}<0.05,{ }^{* * *} \mathrm{p}<0.01$.

and 2/3 of a standard deviation across czones). The effects at the state level are quantitatively smaller (compare columns (4)-(6) to (1)-(3)), but overall these relationships are significant, economically as well as statistically. Therefore, the middle segment of Table 3 confirms Empirical Prediction 2 in our data; an increase in the experience supply reduces the relative employment rate of more experienced workers.

Finally, the bottom segment of Table 3 provides the same instrumental variables regressions as the middle segment with the return to experience according to full-time wages as the outcome variable. Again, the relationship becomes more negative with the IV compared to the OLS, which suggests that the former is in fact able to remove 
variation in actual experience and the outcome variable that is due changing demand for experience (and goes in hand with rising returns to experience). The effect is also highly statistically significant and quantitatively reasonably strong at the czone level. For example, in the first column of the bottom segment, a one year higher average experience (5/8 of a standard deviation of 1.6 , see Table 1$)$ leads to a $0.08 \log$ point lower return to experience (1/3 of a standard deviation). At the state level, the effect is qualitatively similar, but weaker and not statistically significant (it is borderline significant at the ten percent level in column (5)). However, overall the results in the bottom segment of Table 3 confirm Empirical Prediction 3 in our data; an increase in the experience supply reduces the return to experience. The substantial size of the experience supply effect is illustrated in Section 5 below, comparing it quantitatively to other factors that have worked on both the employment gradient and wage return to experience.

\subsection{Robustness Checks}

The previous section has confirmed our Empirical Predictions 1-3 in the data; that higher experience supply should lead to higher actual experience but by less than oneto-one, lower full-time employment rates of experienced workers, and a lower wage return to experience. We show in this section that these results are robust to various alternative empirical specifications and sample definitions. Just as in our baseline analysis, we first construct for each specification and sample a LLM-year panel in which we then study the outcomes of interest using our instrumental variable strategy.

\subsubsection{Alternative Specifications}

\section{"Structural" Individual Wage Regressions:}

The general approach of this paper is to test the theoretical predictions about the effects of labor market aging using standard linear wage and choice regressions, but not to estimate the model of Section 2 structurally. For readers who would like regression specifications closer to the original framework by Jeong, Kim, and Manovskii (2015), we also estimate the individual-level wage regression to obtain the return to experience from the theoretical model's Equation (4), which unlike (15) does not ap- 
proximate $\ln \left(1+p e_{j}\right) \approx p e_{j}$, using nonlinear least squares: ${ }^{25}$

$$
w_{j l t}=\alpha_{j l t}^{p}+\ln \left(1+p_{l t}\right) e_{j l t}+\beta_{l t}^{p} x_{j l t}+u_{j l t}^{p} .
$$

In the resulting LLM-year panel we then estimate (16). Table A3 in the Appendix reports the results. These are qualitatively very similar to the ones reported in Table 3 (the unreported IV first stage is also quantitatively very similar to that table), but the coefficients are larger and with higher statistical significance than in our main specifications. Therefore, we consider our baseline results in Section 2.2, based on the approximation of Jeong, Kim, and Manovskii (2015)'s structural log wage equation, as conservative.

We have also estimated the individual-level choice regressions (14) under the explicit assumption that error terms are normally distributed or type 1 extreme value distributed. These probit and logit choice regressions, respectively, have yielded very similar results to Tables 3 and A3.

\section{Splitting Workers into Discrete Experienced versus Inexperienced Groups:}

A striking feature of our approach is the linearity in experience $\left(e_{j l t}\right)$ of the individuallevel choice and wage regressions (14) and (15). As explained in Section 3.2, this carries the advantages that we obtain one experience-gradient and one wage return to experience for every LLM-year, and that we can empirically exploit fine-grained information in workers' experience. Here, we present alternative estimation results with dummy regressors that split the workforce into an inexperienced (less than 20 years potential experience) and an experienced (20 years or more potential experience) group, similar to Caselli (2015). ${ }^{26}$ Assigning dummies $e_{j l t} \in\{0,1\}$ to inexperienced and experienced workers, we run regressions (14) and (15) to again remove the effects of confounders.

\footnotetext{
${ }^{25}$ If we assume level wages to be of the form $w_{j}=w^{I}\left(1+p e_{j}\right)$ and reservation wages as $\underline{w}_{j}=w^{I} \gamma e_{j}$, we get for the full-time dummy $f_{j}=\mathbb{1}\left[1+r e_{j}>0\right]$ with $r \equiv(p-\gamma)$ and the choice regression is still of the form (14). In Table A3 we additionally report results from estimating this as:

$$
f_{j l t}=\alpha_{j l t}^{r}+\ln \left(1+r_{l t}\right) e_{j l t}+\beta_{l t}^{r} x_{j l t}+u_{j l t}^{r} .
$$

${ }^{26}$ We use the same cutoff as Caselli (2015), with the median and the mean of potential experience in his as well as our dataset at around 20 years.
} 
Table A4 in the Appendix reports the results. The IV first stages in columns (1) and (4) are again positive and statistically significant. ${ }^{27}$ The second stage results for the experience gradient and the return to experience are also negative, consistent with Empirical Predictions 2 and 3. For example, in column (2) a ten percentage point higher share of experienced workers (10/7 of a standard deviation) leads to a 0.046 lower relative full-time employment rate of experienced workers (mean 0.07, standard deviation 0.04 ). It also leads to 0.17 lower relative wage of experienced workers (mean 0.28 , standard deviation 0.05 , see column (3)). That these effects are not statistically significant, however, is not surprising given that the estimation uses much less empirical information than our linear in years-of-potential-experience baseline specifications (14) and (15).

\section{Controlling for State and Year Interactions on the Commuting Zone Level:}

One concern about our empirical strategy could be that there might be policies at the state level, or other time-varying factors, that are correlated with demographic change and at the same time affect the experience gradient or the return to experience. For example, there are a whole range of state employment policies, for instance minimum wages and eligibility criteria for unemployment insurance or workers' compensation (see U.S. Chamber of Commerce (2011) for a summary), and if these were correlated with demographic change, our results might be biased.

We therefore explore a version of the regressions at the czone level in which we flexibly control for state-year changes by including dummies for states, years and their interactions. Appendix Table A5 shows the results. This is a demanding specification, as it allows identification based only on differential variation across commuting zones over time within state-year cells. Nonetheless, the effects in Table A5 of experience supply on the full-time gradient and on the return to experience are qualitatively the same, but quantitatively and statistically even stronger than in our main Table $3 .^{28}$ Therefore, our baseline specifications are robust to changes in time-varying confounding

\footnotetext{
${ }^{27}$ Because it is more fine-grained and statistically more powerful, we use predicted average experience as instrument like in Table 3 instead of the predicted share of experienced workers.

${ }^{28}$ The unreported IV first stage of experience supply on its prediction from the previous census is smaller in absolute value than in Table 3, but it remains statistically significant at p-values above 1 percent in all regressions. Overlapping commuting zones are again assigned to the state with the highest share of employment. We cluster standard errors at the czone level here, because these specifications already directly control for factors that vary across states $\times$ years.
} 
factors at the state level and we consider them to be conservative also in this respect.

\section{Controlling for Demographic and Employment Characteristics:}

As a further robustness check, we include in the panel estimation additional controls to address the potential concern that our results might be driven by a third factor that is correlated with our identifying variation but that we have not controlled for. In Table 3 we already added years of education, whereas now we control for key demographic characteristics and the structure of employment in terms of industries and occupations. ${ }^{29}$ Appendix Table A7 shows the results when controlling for the contemporaneous full-time employment shares of black and of female individuals, as well as the share of employment in goods-producing (i.e. not in services) sectors and in routine occupations. ${ }^{30}$

In the first segment we see that the first stage of the IV remains very strong, also conditional on the LLMs' contemporaneous occupation and industry structure, and when adding education and demographics as further controls. The middle segment reports the main results with respect to the experience gradient of full-time employment. With these additional controls, the coefficients at the czone level slightly decline and they slightly increase at the state level, where also statistical significance is somewhat higher, but overall the results are very similar to our main results in Table 3. The bottom segment of Table A7 reports the effect on the wage return to experience. Again, including controls for the demographic and employment structure hardly affects the estimates. The experience gradient of wages remains virtually unchanged, and the results at the state level once more become slightly more significant.

The results in Appendix Table A7 are generally robust to permutations of these control variables as well as to controlling for their shares in the broader employment population or the overall workforce. This suggests that our results are not driven by third factors.

\section{Estimation in First Differences:}

Finally, we explore an alternative specification of our estimation in first differences.

\footnotetext{
${ }^{29}$ Note though that changes in these variables (by LLM and year), especially in the occupation and industry structure, very well might be outcomes of the economic mechanism that we are interested in.

${ }^{30} \mathrm{We}$ focus in the industry dimension on goods production and in the occupation dimension on routine, as both have declined considerably over the past six decades, at least at the U.S. federal level (Bárány and Siegel, 2018).
} 
Appendix Table A6 presents the results. The unreported first stage coefficients are weaker than in Table 3, but still statistically significant at the one percent level. We see that the effects of the changes in experience supply on the changes in the outcome variables are qualitatively the same as in the corresponding fixed effects specifications. The effect on the return to experience is even stronger than in our main Table 3 and statistically more significant. The point estimate on the full-time employment gradient is quantitatively similar, although admittedly statistically insignificant throughout. This may be because we lose some observations due to first differencing, ${ }^{31}$ but also because fixed effects estimates are more efficient if the error terms in the estimation are serially uncorrelated. In addition, the effects obtained in the first-difference model on labor force participation are of the same size and significance as in columns (1) and (4) of Table 4 below (not reported for brevity). We therefore conclude that our main empirical results are largely robust to estimation in first differences.

\subsubsection{Alternative Samples}

\section{Males only:}

Next we restrict our sample to men only. We do this robustness check, as arguably over the time horizon we study there have been many changes to female participation, and perhaps wages too, that may confound our analysis.

Table A8 in the Appendix reports the results for the men-only sample. These are stronger than the ones for the whole sample in Table $3 .{ }^{32}$ This may be due to women's labor market outcomes being driven to a larger degree by other factors that might have changed over time. To note is that in this analysis we only took the variation in male experience supply when studying the effect on (men's) full-time employment and return to experience. As it is conceivable that the also rise in female participation, in particular higher levels of experience, also impacted men, we have also studied labor outcomes for men when the overall variation in experience supply stems from both male and female workers. The results were again rather similar.

\footnotetext{
${ }^{31}$ We see that because of the differencing the number of observations have dropped. In the log-log regressions (columns (3) and (6)) we lose further observations, since a negative experience gradient either in $t$ or $t-10$ implies a missing value.

${ }^{32}$ Unreported is the IV first stage, which is similarly strong to Table 3.
} 


\section{Separate Analysis for College and High-School Workers:}

Finally we split the sample by educational attainment. In our main analysis, motivated by the model proposed by Jeong, Kim, and Manovskii (2015), we pooled together workers with different education levels, and thereby treated them as perfect substitutes. As already discussed, there are many advantages to this framework; in particular it avoids having to take a stance on whether workers with different experience but the same education are closer (or even perfect) substitutes than those with same education but different experience. An alternative approach would be to study how changes in the experience supply of workers with a given education affect outcomes for workers within that educational category. In our multistep framework this corresponds to running the whole analysis separately for each group.

We do this in Appendix Table A10, which shows the results for college and highschool workers separately. For both education groups the effects on the full-time gradient and on the return to experience are qualitatively the same to each other and to the main results in Table 3. They are also quantitatively close, albeit a bit stronger for high-school workers. We view this similarity in the estimates as a further justification for pooling workers with different education together in our main analysis. The effects are also statistically significant on the commuting zone level.

\section{Composition Effect of the Changing Experience Structure:}

One more fundamental concern for our results is that the population's evolving age distribution may lead to changing returns and full-time gradients of experience due to a mechanical composition effect, rather than an economic response. True life-cycle profiles are in fact hump shaped, with lower employment rates and to some extent lower wages for individuals that are nearing retirement. ${ }^{33}$ Therefore, if average experience rises, the mass of the population may shift from prime age with high employment rates to older ages with lower such rates. This composition effect potentially could generate our results even when actual employment or wage rates are constant at given years of potential experience.

To check our results for robustness we therefore employ a reweighing strategy in

\footnotetext{
${ }^{33}$ In our view, this is not generally problematic for our approach beyond the specific concern at hand, since we are not interested in life-cycle profiles' levels or shapes but in their rotations (i.e. changes of average gradients) due to rising experience supply.
} 
order to remove the possible composition effect. In particular, we use the method proposed by DiNardo, Fortin, and Lemieux (1996, henceforth DFL) to reweigh observations such that demographic characteristics of individuals within each local labor market and year remain the same as in 1980. We estimate the micro-level regressions (14) and (15) on this sample, which by construction holds the demographic composition constant. ${ }^{34}$ The resulting panel of experience-employment gradients and wage returns to experience are then used as the outcome variables in regression (16), where we investigate the effects of the actual experience supply $\left(\frac{E_{l t}}{I_{l t}}\right)$ at the LLM-level. ${ }^{35}$

Table A9 in the Appendix reports the results. We see that the coefficients for the fulltime gradient are smaller than in our main specification of Table 3, halving for czones. However, they remain the same for states and they are statistically significant at the ten and five percent level, respectively. The coefficients are also strong and significant for the return to experience at the czone level. In unreported analyses we have further examined the effect on labor force participation rates for the reweighed estimation and found similar results as those for the non-reweighed specification in Table 4 below.

We have conducted further checks based on our (non-reweighed baseline) analysis for sub-samples by age; focusing on within prime age (25-54) and between old (16-24) versus young (55-65) workers only, respectively, and thereby ruling out the composition effect described above. The results show that the effect of experience supply on relative employment rates is mainly driven by the latter comparison, which makes sense given that labor force participation and full-time employment are much less stable (and thereby more responsive to economic incentives) for old and young wor-

\footnotetext{
${ }^{34}$ We employ a rich and flexible specification for the reweighing, which consists of a fourth-order polynomial in potential experience interacted with a sex and a college dummy, race dummies, marital status by sex, and a quadratic in years of education. For this we include all individuals who are 13-68 years old in order to obtain a good fit also at the ends of the potential experience range [0,45]. We do this because it is known that polynomial fits at end points might be quite poor but also since the smoothness in the age/experience structure (e.g. due to autocorrelations in birth and death rates) helps to give more accuracy at these ends. Graphically and using summary statistics, we ensure that this procedure is successful, i.e. that for all years the reweighed distributions of potential experience are similar to the actual distribution in 1980.

${ }^{35}$ To be clear, in the panel analysis we are using the same variation in actual experience supply across LLMs and years as in our baseline analysis; the difference here is that the dependent variable, the fulltime gradient or the wage return, are constructed from micro-level estimations on reweighed data such that they cannot be mechanically confounded by changes in composition, but they still vary across LLMs and across years due to economic responses.
} 
kers than for prime age individuals. ${ }^{36}$ Finally, we have examined the effect on narrow five-year experience bins, finding that every experience bin is negatively affected by rising experience supply compared to the baseline of $0-4$ years, but the highest bin most strongly so.

We only explicitly report the results from DFL reweighing here, since it is the direct way to address composition concerns and most consistent with our economic framework in which all individuals with some positive experience are affected by experience supply changes. Nonetheless, these different empirical tests show that our results are qualitatively robust to composition effects due to shifting experience structure, indicating that our results are indeed due to an economic response.

\subsection{Effects on Employment Status, Migration, and Program Claims}

Finally, we study the employment response to demographic change in further detail by analyzing the effect on overall employment (including part-time and temporary work), labor force participation, unemployment, and migration (across local labor markets), as well as welfare and social security income or whether the person identifies themselves as suffering from a disability.

We start by investigating the effect of experience supply on labor force participation (LFP), unemployment status, and migration (into a local labor market). Just as before we are interested in studying how workers with different experience are affected differentially. We therefore first estimate (14) for each outcome to obtain for each of them a gradient with respect to experience, which captures by how much an extra year of experience changes a worker's probability of being in the labor force, unemployed, or of having migrated into this LLM. In the resulting LLM-year panels we then estimate (16) for these outcome gradients using our instrumental variable strategy.

Table 4 shows the results. In column (1) the effect on the LFP gradient of experience is qualitatively the same, but about fifty percent stronger in levels than for full-time

\footnotetext{
${ }^{36}$ Moreover, the economic model of Section 2 suggests that experience supply changes have the strongest impacts on workers at the extremes of the experience range. When for instance the (local) experience supply rises, this affects all individuals with some experience but it should have the strongest adverse effect on those with the highest experience, as there are more substitutes for their skills available. Conversely, workers with very little experience are the most likely to gain in relative terms from a higher supply of experience.
} 
employment in Table $3 .{ }^{37}$ In column (2), the effect on the unemployment gradient is actually negative, but small and statistically insignificant. The difference between the effect on the LFP and on the unemployment gradient yields the effect on the overall employment gradient (where employment comprises not only of full-time full-year workers as in Sections 4.1 and 4.2, but also includes part-time and temporary work), which is equal to -0.15 , both in the czone and the state panel, and not explicitly reported in the table due to space.

Table 4: Effect on Participation, Unemployment, Migration, and Program Claims

\begin{tabular}{|c|c|c|c|c|c|c|}
\hline & (1) & (2) & (3) & (4) & (5) & (6) \\
\hline Empl\&Migratn & LF-Particp & Unemplnt & In-Migrtn & LF-Particp & Unemplnt & In-Migrtn \\
\hline \multirow[t]{2}{*}{ Avg Experience } & $-0.16^{* *}$ & -0.01 & -0.09 & $-0.17^{* * *}$ & $-0.02^{* *}$ & -0.06 \\
\hline & $(0.08)$ & $(0.01)$ & $(0.06)$ & $(0.05)$ & $(0.01)$ & $(0.05)$ \\
\hline Program Claims & Soc-Secrty & Disability & Welfare & Soc-Secrty & Disability & Welfare \\
\hline \multirow[t]{2}{*}{ Avg Experience } & $0.07^{* * *}$ & 0.02 & -0.00 & $0.07^{* *}$ & 0.02 & $-0.01^{*}$ \\
\hline & $(0.02)$ & $(0.02)$ & $(0.01)$ & $(0.03)$ & $(0.02)$ & $(0.01)$ \\
\hline Obs (Emp\&Mgr) & 2888 & 2888 & 2888 & 304 & 304 & 304 \\
\hline Obs (Prg Clms) & 2888 & 2888 & 2888 & 255 & 255 & 255 \\
\hline Fixed Effects & czone+year & czone+year & czone+year & state+year & state+year & state+year \\
\hline Sample & $\geq 1980$ & $\geq 1980$ & $\geq 1980$ & $\geq 1960$ & $\geq 1960$ & $\geq 1960$ \\
\hline
\end{tabular}

The top segment of the table reports results from the second-stage estimation (16) with employment and migration related outcomes: the labor force participation gradient of experience, the unemployment gradient, and the in-migration gradient. The bottom segment reports the social security income (including pension and disability) gradient, self-identified disability gradient, and the welfare income (including GA and SSI) gradient of experience. The first stage of the IV is the same as in the top segment of Table 3. Robust standard errors in parentheses are clustered on state: ${ }^{*} \mathrm{p}<0.1,{ }^{* *} \mathrm{p}<0.05,{ }^{* * *} \mathrm{p}<0.01$.

Two remarks are in order about these results. First, that the overall employment effect is exclusively on LFP is in line with our theoretical model. When the equilibrium price of experience falls, wages offered to more experienced workers are lower which induces some of them to decide not to work (instead of registering as unemployed). This is also supported by the positive effect on social security income (this includes disability and pension claims in our data) reported in the bottom segment of Table 4 and discussed below, which may attract experienced workers out of the labor force. Second, that the effect is even stronger for overall employment than for full-time employment (in Table 3), the outcome we focus on as our baseline, is another reason why

\footnotetext{
${ }^{37}$ In terms of standard deviations, they are comparable, i.e. a 1.6 years ( 1 standard deviations) increase in average experience reduces the LFP gradient by 0.25 percentage points (1.3 standard deviations); see Tables 1 and A11 and remember that in these descriptive and in the regression tables $100 \times$ the outcome variable is reported.
} 
we view our baseline results as conservative. The relative magnitude of these effects is consistent with a situation in which part-time or temporary workers are closer to the margin of participating in the labor market at all than full-time full-year workers are to the margin of choosing part-time or temporary work, or to not participate. Heterogeneity across different types of workers is studied further in Table A1, where we split the effects by skill groups.

In columns (3) and (6) at the top of Table 4 we report the effect of experience supply on the in-migration gradient into the respective local labor market. The effect on this variable is in the direction that we predicted in Figure 3, that is, there is a lower relative inflow of experienced workers into LLMs that are relatively experience-abundant. The effect is also quantitatively substantial, as a one standard deviation (1.6 years) increase in average experience leads to a ca. $2 / 3$ of a standard deviation $(0.15$, see Table A11) lower experience gradient of in-migration. However, it is not statistically significant at conventional levels.

The bottom segment of Table 4 investigates some of the constituting components of these responses. ${ }^{38}$ In the interpretation of these results it is important to bear in mind that our sample includes individuals of age 16 to 65 , such that all gradients with respect to experience capture the differential responses within the working-age population. Columns (1) and (4) show that the social security gradient rises quantitatively and statistically significantly with experience supply at the local level. This means that higher average experience in the LLM leads to a higher fraction of experienced workers drawing pension or disability insurance income (or a lower fraction of young workers doing so), thereby reducing experienced workers' relative labor market participation rates. In particular, a one standard deviation (1.6 years) increase in average experience raises the experience gradient of receiving payments from social security by almost a standard deviation (0.1, see Table A11).

Since the social security income variable in the Census does not distinguish be-

\footnotetext{
${ }^{38}$ Information on welfare and social security income as well as self-identified disability are not available in 1960, which reduces the number of observations at the state level. We also harmonized somewhat different definitions of disability and migration for 2010 with the previous years. As one would expect given the U.S. retirement rules, which stipulate that workers can draw retirement benefits from age 62, the share of people who report receiving social security income in the data trebles to 32 percent from age 61 to 62 and then increases rapidly to 67 percent at age 65 . However it is worth to note that there are a substantial number of claimants of all ages in our sample, consistent with the inclusion of disability insurance income in this variable.
} 
tween pensions and disability insurance, we examine whether a worker identifies themselves as having any lasting physical or mental condition that causes difficulty working. The effect on this disability outcome (columns (2) and (5)) is also positive, albeit not statistically significant. On the other hand, the effect on the welfare variable, which includes General Assistance (GA) and Social Security Income (SSI), is actually weakly negative (columns (3) and (6)). This parallels our finding on unemployment above and is again consistent with our model where, when local experience supply rises, experienced workers themselves decide not to work, drawing relatively generous disability (e.g. Autor and Duggan, 2003) or pension (at age 62+) income as opposed to meager GA or SSI benefits, which are also demanding in terms of eligibility.

In Appendix A we use skill measures based on education and earnings to examine whether the effects of demographic change on employment, labor force participation, and migration are heterogeneous across skills. We find some mild evidence that experience supply changes affect lower-skilled workers more strongly. In particular, our results suggest that the effect on in-migration stems mostly from lower-skilled experienced workers who become less likely to migrate into local labor markets where experience is abundant. However, we find no strong evidence for differences in the labor force participation response across education groups, whereas across last year's earnings there is some evidence, albeit only at the ten percent level, that individuals without earnings are affected the most.

\section{The Race between the Supply and Demand for Expe- rience}

This final section uses our estimates in order to assess the contribution of demographic change to the aggregate evolution in the experience gradient of full-time work and the wage return to experience over the last fifty years. To do this we focus on the averages of these outcomes and of the local experience supply at a given point in time, which is consistent with the notion that production takes place at the level of local labor markets, as we assumed throughout the paper.

In particular, we are interested in what drives the evolution in the wage return and 
the full-time gradient of experience over time, starting from the first year for which we can construct these, i.e. 1970 for commuting zones. We therefore average Equation (16) over local labor markets (weighted by relative size as throughout the paper; see footnote 16) to obtain for the change over time:

$$
\Delta \overline{\text { outcome }}_{t}=\underbrace{\eta \Delta \overline{\left(\frac{E_{t}}{I_{t}}\right)}}_{\text {supply effect }}+\underbrace{\Delta D_{t}+\Delta \overline{\text { error }}_{t}}_{\text {other effects }},
$$

where $\Delta$ denotes the change between the census years $t$ and $t-10$ and $\overline{\text { outcome }}$ is the average outcome (i.e. either experience gradient or return to experience) that we aim to decompose. On the right hand side, the terms can be grouped into two components. First, $\eta \Delta \overline{\left(\frac{E_{t}}{I_{t}}\right)}$ represents the contribution of the effect from changing experience supply to the outcome. This is the product of the coefficient $\eta$, which we estimated for commuting zones in column (1) of Table 3, and of the change in the average experience supply $\Delta \overline{\left(\frac{E_{t}}{I_{t}}\right)}$.

The second component is the remainder of the right hand side of Equation (18), which comprises all other factors. It contains the change in the aggregate time effect $\Delta D_{t}$, which reflects aggregate factors other than supply, such as changes in demand, policies, or society at the nation-wide level, that generate a difference between the outcome in a given year and its initial level in 1970. Finally, $\Delta \overline{\text { error }}_{t}$ is the change in the average of all local labor market-specific deviations from the aggregate time effect, which our instrumental variable strategy ensures to be independent from the LLMspecific supply effect. ${ }^{39}$ The two terms in this second component together therefore reflect all other factors than changes in the supply of experience that have affected the evolution of the experience gradient of full-time work or the wage return to experience over time. They might for example capture biases in technology towards experience, but also changing preferences or regulations with respect to retirement that affect the relative incentives to work or the relative pay of experienced individuals.

In Figure 4 we show the decomposition of the outcomes wage return to experience (top panel) and full-time employment gradient (bottom) into the two components ac-

\footnotetext{
${ }^{39}$ Note that when averaging Equation (16) over local labor markets, there is also the a time-invariant average effect across local labor markets, $\overline{D_{l}}$, which is related to the level of the outcome variable in 1970 and thus $\Delta \overline{D_{l}}=0$.
} 
cording to Equation (18), using the estimates from the commuting zone panel (results for the state panel are in Appendix Figure A2). The solid lines in both panels of the figure represent the evolution of the experience gradient of full-time work and the wage return to experience from 1970 to 2010 (the left-hand side of Equation (18)), respectively. During the first 20 years of the sample, the wage return to experience rises strongly, while the experience-employment gradient (i.e. the relative full-time employment rate of experienced workers) declines. After that, the experience gradient and the return to experience are approximately flat.

The first two decades in Figure 4 underline why it is difficult to evaluate the effect of demographic change on either relative wages or employment rates in aggregate data alone. That is, in a demand and supply model, the return to experience as well as the experience-employment gradient should rise at the same time when they become more productive (demand shock) and they should fall when they become more abundant (supply shock; as verified above). The strongly rising wages and the falling employment rates of experienced workers during the 1970s and 1980s must therefore stem from other factors outside the model. These may include (early) retirement and disability policies, a changing (distribution of) private wealth accumulation and preferences for working, or labor market entry of women. ${ }^{40}$ In addition, cyclical and secular overall changes in labor force participation and unemployment may also affect the relative shares of experienced and inexperience workers in (full-time) employment.

Our identification strategy therefore exploits the local labor market level in order to clean the effect of experience supply from other aggregate factors (using year fixed effects $D_{t}$ ), local factors (using LLM fixed effects $D_{l}$ ), and from changes that vary across locations and time (using predicted experience as an instrument for supply). The red dashed lines in Figure 4 depict the resulting effect of experience supply on the experience-employment gradient and the wage return to experience $\left(\eta \Delta \overline{\left(\frac{E_{t}}{I_{t}}\right)}\right.$ from Equation (18)). The dotted green lines depict the residual, that is, all the other factors including demand for experience, which have driven the wage return and the employ-

\footnotetext{
${ }^{40}$ For example, there was a falling and then a rising access to- and attractiveness of disability programs during the 1970 to 1990s as discussed in Autor and Duggan (2003). In addition, Autor, Duggan, Greenberg, and Lyle (2016) show a large effect of disability eligibility on labor force participation for Vietnam era veterans in 2001. In Figure 2 above, such factors, which affect different experience groups differently, constitute (potentially simultaneous) shifts of the supply and demand curves for relative experience that are different from shifts that are due to demographic change.
} 
Figure 4: The Race Between Supply of Experience and Other Factors (Czone Estimates)

(a) The Aggregate Wage Return to Experience

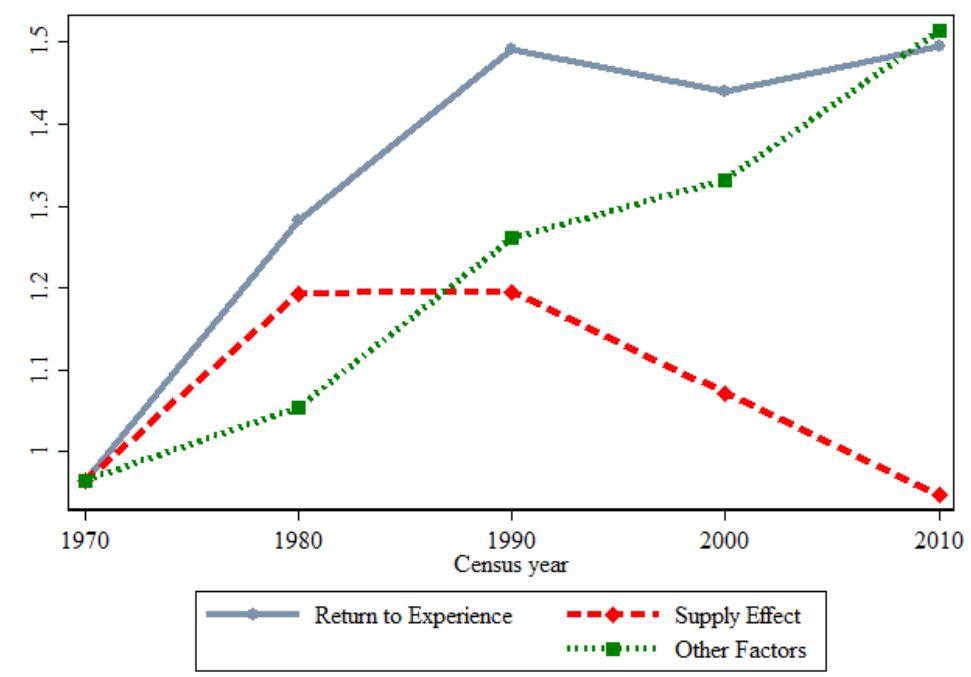

(b) The Aggregate Full-time Employment Gradient of Experience

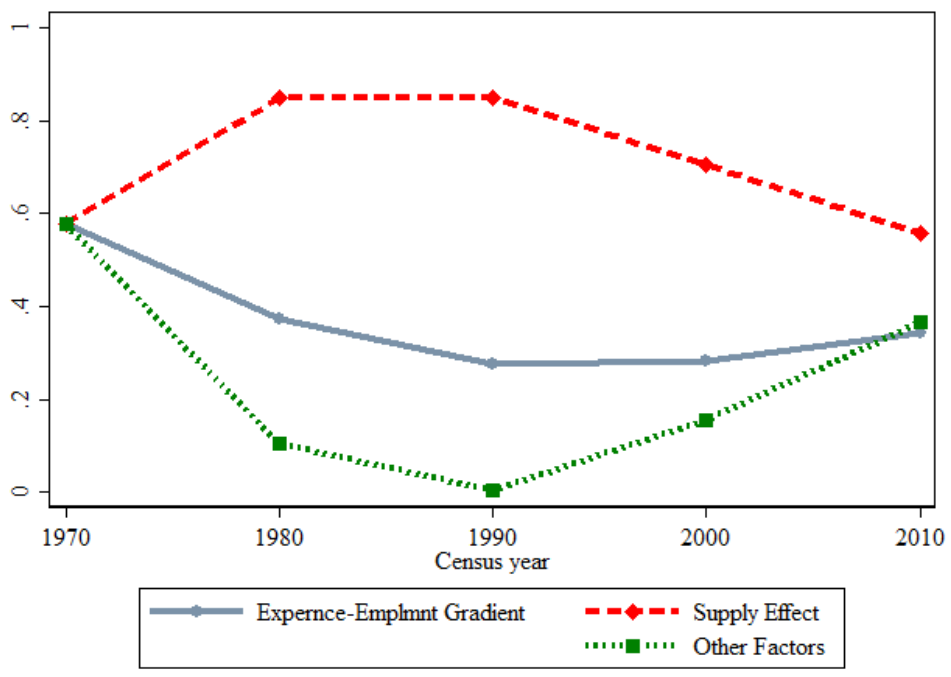

Supply effect and other factors (including demand) using the IV estimates for the panel of commuting zones in 1970-2010 (column (1) of Table 3).

ment gradient of experience $\left(\Delta D_{t}+\Delta \overline{\operatorname{error}}_{t}\right)$.

We see in both panels of the figure that the effects of experience supply on relative wages as well as on relative employment rates point in the same direction. That is, they are a force that raises both variables during the 1970s and 1980s and a force that lowers them both during the 1990s and 2000s. This is in line with our theoretical reasoning and the demand and supply model of Section 2. Moreover, the effect is quantitatively 
strong in the sense that the effect of supply is varying to a similar extent as the actual change in the respective outcome variable in both diagrams.

We now focus on Panel (a) of Figure 4. In the 1970s, as in Jeong, Kim, and Manovskii (2015), the supply effect is positive and it explains most of the rising wage return to experience during this decade. However, since 1980 the positive contribution of other factors to the experience return has much accelerated. Most of the long-run increase in the price of experience is due to this other factor since 1980, which is in line with Katz and Murphy (1992)'s findings who interpret it as demand for experience. It is also consistent with the recent result of Caselli (2015) who argues using time series data that technological progress has been experienced-biased. With our new identification approach, we unveil that such purported experience-biased demand was particularly strong during the 1980s, when it raised the return to experience substantially. It was also particularly strong during the 2000s; otherwise the return to experience would have fallen over the last two sample decades because of demographic change.

In Panel (b) of Figure 4 we see that due to the baby boom and the entry of many young workers into the labor market, the employment gradient of experience should have risen during the 1970s. However, it appears that other factors, which may include policy changes or societal preferences for working at older ages, have reduced the aggregate employment gradient of experience even more strongly (e.g. more lenient access to disability insurance after 1984; see Autor and Duggan, 2003). Conversely, during the 1990s and 2000s, when experienced workers' relative full-time employment rates were pushed down by an aging workforce, other factors led to them remaining virtually constant. In line with the discussion of Panel (a) of this Figure, these other factors may include experience-biased demand as well as policies that have raised the incentives to extend working lives. ${ }^{41}$

Overall, it seems that demographic change has had a substantial effect on aggregate relative wages and employment rates of experienced workers when it is cleaned of other important factors that may have affected these variables on an economy-wide level. Some of these factors could in fact be a response to demographic change, such

\footnotetext{
${ }^{41}$ Note that despite more positive trends in overall than in male full-time employment rates, the trends in the experience gradient of full-time employment depicted for both genders in Figure 4 is qualitatively similar for males only (available upon request).
} 
as early retirement programs in the 1970s and 1980s and their phasing out during the decades after that (e.g. Lee, 2016), or technological change at the aggregate level as in Acemoglu (1998). Our estimation approach uncovers only the supply effect, but we think this is a necessary first step for understanding the interplay between all these variables.

\section{Conclusion}

In this paper we consider the impact of demographic change on the labor market, explicitly taking the employment margin into account. We show that population aging not only reduces experienced workers' relative wages, as established in existing literature, but also affects negatively and strongly their relative full-time employment rates. We further investigate this novel effect in more detail and find that it is fully driven by experienced workers' labor force participation, rather than unemployment. This supports our theoretical model's assumption that workers themselves decide whether to work according to a reservation wage equation. We also demonstrate that our main results are robust to alternative estimation specifications and samples, and that a substantial part of the effect of experience supply on relative employment rates is through claiming social security income.

Given our estimates, we evaluate the contribution of experience supply to the U.S. aggregate evolution of the wage return and the employment gradient of experience over the last decades. We find that the experience supply effect is quantitatively strong, in the sense that the variation it induces is about as large as the overall variation in the outcomes. However, when considering the race between the supply effect and other (aggregate) factors we see that these have often worked in opposite directions, especially for the employment gradient. This highlights that our novel identification strategy, based on local labor markets and instrumenting experience supply by the previous age structure, is important in disentangling the effect of experience supply from other factors.

Our findings also suggest that policymakers should take note of the previously unrecognized effect on relative employment rates. Prior research has found that improvements in health and education, societal changes, as well as policies with respect 
to retirement or age discrimination have been important in determining the evolution of older workers' participation rates over the last decades (e.g. Blau and Goodstein, 2010; Maestas and Zissimopoulos, 2010; Neumark and Song, 2013). We show that there is also an important market force stemming from the supply of experience. In turn, this has implications for evaluating recent policy proposals in the face of population aging, such as to raise the retirement age or to incentivize voluntary participation of older workers (summarized in Lee, 2016). In particular, our results suggest that such policy changes would have different effects in labor markets that are relatively young than in those that are old, and in which experience is rather abundant. While recent policy changes have counteracted these effects to some degree already (e.g. as summarized in Coile, 2018), our paper provides systematic evidence for why such reforms were indeed needed from the perspective of the social security system.

\section{References}

Acemoglu, D. (1998): "Why Do New Technologies Complement Skills? Directed Technical Change and Wage Inequality," Quarterly Journal of Economics, 4, 1055-1089.

Autor, D. H., AND D. Dorn (2012): “The Growth of Low Skill Service Jobs and the Polarization of the U.S. Labor Market," American Economic Review, 103(5), 1553-1597.

Autor, D. H., D. Dorn, And G. H. HANSON (2013): “The China syndrome: Local labor market effects of import competition in the United States," The American Economic Review, 103(6), 2121-2168.

Autor, D. H., M. Duggan, K. GreenberG, and D. S. Lyle (2016): “The Impact of Disability Benefits on Labor Supply: Evidence from the VA's Disability Compensation Program," American Economic Journal: Applied Economics.

Autor, D. H., And M. G. DugGan (2003): "The Rise in the Disability Rolls and the Decline in Unemployment," The Quarterly Journal of Economics, 118(1), 157-206.

BAileY, M. J. (2010): “"Momma's Got the Pill": How Anthony Comstock and Griswold v. Connecticut Shaped US Childbearing," American Economic Review, 100(1), 98-129. 
BÁRÁNY, Z. L., AND C. SIEGEL (2018): “Job Polarization and Structural Change," American Economic Journal: Macroeconomics, 10(1), 57-89.

Blau, D. M., AND R. M. GoOdstein (2010): “Can social security explain trends in labor force participation of older men in the United States?," Journal of human Resources, $45(2), 328-363$.

Bronson, M. A., AND M. MAZzOCCO (2016): “Cohort Size and the Marriage Market: Explaining Nearly a Century of Changes in U.S. Marriage Rates," Discussion paper.

CARD, D., And T. Lemieux (2001): “Can Falling Supply Explain The Rising Return To College For Younger Men? A Cohort-based Analysis," Quarterly Journal of Economics, 116(2), 705-746.

CASElLI, F. (2015): “Experience-biased Technical Change,” LSE, mimeo.

COILE, C. (2018): “Working Longer in the U.S.: Trends and Explanations," Working Paper 24576, National Bureau of Economic Research.

DiNardo, J., N. M. Fortin, AND T. Lemieux (1996): “Labor Market Institutions and the Distribution of Wages, 1973-1992: A Semiparametric Approach," Econometrica, 64(5), 1001-1044.

DUSTMANN, C., U. SCHÖNBERG, AND J. STUHLER (2017): “Labor supply shocks, native wages, and the adjustment of local employment," The Quarterly Journal of Economics, 132(1), 435-483.

Freeman, R. B. (1979): “The Effect of Demographic Factors on Age-Earnings Profiles," The Journal of Human Resources, 14(3), 289-318.

JeOng, H., Y. Kim, And I. Manovskit (2015): “The Price of Experience," American Economic Review, 105(2), 784-815.

JONES, L. E., And M. TERTilt (2008): “An Economic History of Fertility in the U.S.: 1826-1960," in Frontiers of Family Economics, ed. by P. Rupert, vol. 1, pp. 165-225. Elsevier. 
KATZ, L. F., And D. H. AutOR (1999): “Changes in the Wage Structure and Earnings Inequality," Handbook of Labor Economics, 3, 1463 - 1555.

KATZ, L. F., AND K. M. MurPhy (1992): “Changes in Relative Wages, 1963-1987: Supply and Demand Factors," Quarterly Journal of Economics, 107(1), 35-78.

LEE, R. (2016): “Macroeconomics, Aging, and Growth," Handbook of the Economics of Population Aging, 1, 59-118.

Maestas, N., K. J. Mullen, And D. Powell (2016): “The Effect of Population Aging on Economic Growth, the Labor Force and Productivity," Working Paper 22452, National Bureau of Economic Research.

Maestas, N., AND J. Zissimopoulos (2010): “How longer work lives ease the crunch of population aging," The Journal of Economic Perspectives, 24(1), 139-160.

NEUMARK, D., AND J. SONG (2013): “Do stronger age discrimination laws make Social Security reforms more effective?," Journal of Public Economics, 108, 1-16.

Ruggles, S., J. T. Alexander, K. Genadek, R. Goeken, M. B. Schroeder, and M. SobeK (2010): “Integrated Public Use Microdata Series,” Discussion paper, Minnesota Population Center, Minneapolis, MN, Version 5.0.

U.S. Chamber of COMmerce (2011): “The Impact of State EmploymentPolicies on Job Growth: A 50-State Review," Report.

WelCH, F. (1979): “Effects of Cohort Size on Earnings: The Baby Boom Babies' Financial Bust," Journal of Political Economy, 87(5), S65-S97. 


\section{Appendix}

\section{A Effects of Demographic Change by Skill Group}

The economic model presented in Section 2 is based on the notion that individuals make a choice whether to work. This implies that the response in workers' employment decisions due to demographic change should be systematic, in the sense that workers with the lowest rents from employment should be the first to leave when their experience group becomes more abundant. These rents are determined by workers' skills (via potential wages) and by their preferences for working (via reservation wages). Since observable skill proxies might also be related to the preferences for working, it is an empirical question how the employment response depends on (observed) skills, which we explore in this section.

In particular, we study how a change in the experience supply impacts the laborforce-participation gradient and the in-migration gradient by skill groups. We define skill groups based on workers' education and alternatively on earnings, which we can do as in our data earnings refer to the previous year (see Section 3.1), whereas the labor force status and the migration flag correspond to the current year. Notice that we cannot do this with the full-time, full-year employment indicator that we analyze in Section 4.1, since it relies on information on hours and weeks worked in the previous year as do the wages. We therefore mainly focus in this section on labor force participation instead, but also report the effects on the full-time employment gradient by education.

Table A1 reports how an increase in average experience in a local labor market affects the various gradients differentially across skill groups. The very top of the table shows the effect of experience supply on the full-time employment gradient by education groups: ${ }^{42}$ columns (1) and (5) are highschool dropouts (for czones and states respectively), (2) and (6) highschool graduates, (3) and (7) attended some college, whereas (4) and (8) attained at least a four-year college degree. There is a negative effect on all of these groups, but there is no monotonicity in educational attainment

\footnotetext{
${ }^{42} \mathrm{As}$ the regressor and the instrument are the same, the first stage of the IV throughout Table A1 is the same as the respective specifications (columns (1) and (4)) in the top segment of Table 3.
} 
Table A1: Effects on LF-Participation and In-Migration by Skill Group

\begin{tabular}{|c|c|c|c|c|c|c|c|c|}
\hline Empl by Educ & $\begin{array}{c}(1) \\
\text { DrpOut }\end{array}$ & $\begin{array}{c}(2) \\
\text { HS-Grd }\end{array}$ & $\begin{array}{c}(3) \\
\text { So-Col }\end{array}$ & $\begin{array}{c}(4) \\
\text { Collge }\end{array}$ & $\begin{array}{c}(5) \\
\text { DrpOut }\end{array}$ & $\begin{array}{c}(6) \\
\text { HS-Grd }\end{array}$ & $\begin{array}{c}(7) \\
\text { So-Col }\end{array}$ & $\begin{array}{c}(8) \\
\text { Collge }\end{array}$ \\
\hline Avg Expernce & $\begin{array}{l}-0.07 \\
(0.05)\end{array}$ & $\begin{array}{l}-0.03 \\
(0.04)\end{array}$ & $\begin{array}{c}-0.12^{* *} \\
(0.06)\end{array}$ & $\begin{array}{c}-0.06 \\
(0.04)\end{array}$ & $\begin{array}{c}1 \\
-0.01 \\
(0.02)\end{array}$ & $\begin{array}{c}-0.16^{* * *} \\
(0.04)\end{array}$ & $\begin{array}{c}-0.12^{* * *} \\
(0.04)\end{array}$ & $\begin{array}{c}-0.15^{* * *} \\
(0.04)\end{array}$ \\
\hline LFP by Educ & DrpOut & HS-Grd & So-Col & Collge & DrpOut & HS-Grd & So-Col & Collge \\
\hline Avg Expernce & $\begin{array}{c}-0.20 \\
(0.15)\end{array}$ & $\begin{array}{c}-0.10^{* *} \\
(0.04)\end{array}$ & $\begin{array}{c}-0.15^{* *} \\
(0.08)\end{array}$ & $\begin{array}{c}0.01 \\
(0.02)\end{array}$ & $\begin{array}{c}-0.16^{*} \\
(0.09)\end{array}$ & $\begin{array}{c}-0.14^{* * *} \\
(0.05)\end{array}$ & $\begin{array}{c}-0.19^{* * *} \\
(0.07)\end{array}$ & $\begin{array}{c}-0.14^{* * *} \\
(0.04)\end{array}$ \\
\hline LFP by LyEarn & None & Terc 1 & Terc 2 & Terc 3 & None & Terc 1 & Terc 2 & Terc 3 \\
\hline Avg Expernce & $\begin{array}{l}-0.13^{*} \\
(0.07)\end{array}$ & $\begin{array}{l}-0.01 \\
(0.02)\end{array}$ & $\begin{array}{c}-0.05^{* *} \\
(0.02)\end{array}$ & $\begin{array}{l}-0.01 \\
(0.01)\end{array}$ & $\begin{array}{c}-0.15^{* *} \\
(0.07)\end{array}$ & $\begin{array}{c}0.01 \\
(0.02)\end{array}$ & $\begin{array}{c}-0.04^{* *} \\
(0.02)\end{array}$ & $\begin{array}{c}-0.04^{* * *} \\
(0.01)\end{array}$ \\
\hline Migr by Educ & DrpOut & HS-Grd & So-Col & Collge & DrpOut & HS-Grd & So-Col & Collge \\
\hline Avg Expernce & $\begin{array}{c}-0.14^{* *} \\
(0.07)\end{array}$ & $\begin{array}{c}-0.05 \\
(0.04)\end{array}$ & $\begin{array}{c}-0.02 \\
(0.03)\end{array}$ & $\begin{array}{l}-0.12^{*} \\
(0.06)\end{array}$ & $\begin{array}{c}-0.12^{* *} \\
(0.05)\end{array}$ & $\begin{array}{c}0.03 \\
(0.07)\end{array}$ & $\begin{array}{c}0.07^{*} \\
(0.04)\end{array}$ & $\begin{array}{c}0.13^{* * *} \\
(0.04)\end{array}$ \\
\hline Migr by LyEarn & None & Terc 1 & Terc 2 & Terc 3 & None & Terc 1 & Terc 2 & Terc 3 \\
\hline Avg Expernce & $\begin{array}{l}-0.11^{*} \\
(0.06)\end{array}$ & $\begin{array}{l}-0.05 \\
(0.04)\end{array}$ & $\begin{array}{l}-0.07 \\
(0.05)\end{array}$ & $\begin{array}{l}-0.10^{*} \\
(0.06)\end{array}$ & $\begin{array}{l}-0.05 \\
(0.04)\end{array}$ & $\begin{array}{c}-0.10^{* *} \\
(0.05)\end{array}$ & $\begin{array}{l}-0.01 \\
(0.07)\end{array}$ & $\begin{array}{c}0.00 \\
(0.05)\end{array}$ \\
\hline $\begin{array}{l}\text { Observations } \\
\text { Fixed Effects } \\
\text { Sample }\end{array}$ & $\begin{array}{c}2888 \\
\text { czn+yr } \\
\geq 1980\end{array}$ & $\begin{array}{c}2888 \\
\text { czn+yr } \\
\geq 1980\end{array}$ & $\begin{array}{c}2888 \\
\text { czn+yr } \\
\geq 1980\end{array}$ & $\begin{array}{c}2888 \\
\text { czn+yr } \\
\geq 1980\end{array}$ & $\begin{array}{c}304 \\
\text { state+yr } \\
\geq 1960\end{array}$ & $\begin{array}{c}304 \\
\text { state+yr } \\
\geq 1960\end{array}$ & $\begin{array}{c}304 \\
\text { state+yr } \\
\geq 1960\end{array}$ & $\begin{array}{c}304 \\
\text { state+yr } \\
\geq 1960\end{array}$ \\
\hline
\end{tabular}

The table reports results from the second-stage estimation (16) for labor force participation (LFP) and inmigration (Migr) by skill group. The top segment shows the effect on the LFP gradient of experience for dropouts, high-school graduates, some college, and college graduates separately. The middle segment shows the effect for individuals with no wages in the previous year and individuals in previous year wage terciles 1-3 separately. The bottom segment shows the effect on the in-migration gradient for fulltime workers with positive wages in the previous year for four wage quartiles separately. The first stage of the IV is the same as in the top segment of Table 3. Robust standard errors in parentheses are clustered on state: ${ }^{*} \mathrm{p}<0.1,{ }^{* *} \mathrm{p}<0.05,{ }^{* * *} \mathrm{p}<0.01$.

discernible.

The next segment of Table A1 shows the effect on the labor force participation gradient of experience for drop-outs, high-school graduates, some college, and college graduates separately, in columns (1) to (4) for commuting zones and (5) to (8) for states. At the czone level it appears that the effect of aging on experienced workers' relative participation is strongest (though insignificant) for the least-skilled workers and non-existent for college graduates. However, at the state level such a difference of the effect across skill groups does not appear.

While education is one measure of skill, it does not capture all forms of human capital. An alternative is to proxy workers' skills by their earnings (in the previous year). We therefore do an alternative skill grouping in which we assign in each LLM- 
year individuals into bins based on their position in the earnings distribution amongst people with the same years of experience. ${ }^{43}$ We create a bin for no earnings at all and one for each tercile of positive earnings.

We see in the middle segment of Table A1 that a substantial share of the negative effect on participation are driven by individuals who did not have any labor earnings in the previous year (columns (1) and (5)), while the effect on the terciles of actual wages is much lower. If not having earned wages last year is a proxy for possessing less of the relevant skills, this suggests that aging affects lower-skilled workers more in their labor force participation than higher-skilled workers. More generally, the effect on participation is such that previously inactive workers become less likely to enter the labor force than previously active workers becoming inactive. ${ }^{44}$

Finally, in the two bottom segments of Table A1 we study the effects on the inmigration gradient by skill group. At the czone as well as at the state level, the relative in-migration of less educated experienced workers declines the most when the LLM experiences an aging shock. In terms of last year's earnings, the effect seems to be largest on individuals without any earnings or for those in the lower tercile, but standard errors are quite large and there is no monotonic pattern overall.

Overall, we find some mild evidence that a rise in experience supply affects labor market outcomes of low-skilled workers more strongly than those of the middle or high-skilled. That we do not find a more discernible pattern in the ranking of the effects by skills, is perhaps not surprising as theory only implies that individuals who are close to indifference of participating are the first to drop out or to enter the labor force when prices change. Whether these are more likely to be low-, middle-, or high-skilled individuals is a purely empirical question.

\footnotetext{
${ }^{43}$ This corresponds to the definition of skills other than experience as $\beta_{1} x_{j}+u_{j}$ in Equation (5).

${ }^{44}$ Accordingly, Dustmann, Schönberg, and Stuhler (2017) find that a migration shock from Eastern Europe mostly reduces previously not employed German workers' transitions into employment rather than increasing transition rates out of employment.
} 


\section{B Additional Tables and Figures}

Table A2: Descriptive Statistics for Population and Full-time Workers Aged 16-65

\begin{tabular}{|c|c|c|c|c|c|c|}
\hline Population & Ln(Wage) & Fulltime & Age & Pot Exper & Yrs Educ & Female \\
\hline \multicolumn{7}{|l|}{1960} \\
\hline mean & 0.50 & 0.33 & 38.4 & 21.8 & 10.3 & 0.51 \\
\hline sd & 1.21 & 0.47 & 13.8 & 14.3 & 3.1 & 0.50 \\
\hline \multicolumn{7}{|l|}{1970} \\
\hline mean & 0.93 & 0.36 & 37.6 & 20.2 & 11.2 & 0.52 \\
\hline sd & 1.22 & 0.48 & 14.5 & 14.9 & 2.9 & 0.50 \\
\hline \multicolumn{7}{|l|}{1980} \\
\hline mean & 1.61 & 0.43 & 36.6 & 18.4 & 12.0 & 0.51 \\
\hline sd & 1.22 & 0.49 & 14.4 & 14.6 & 2.7 & 0.50 \\
\hline \multicolumn{7}{|l|}{1990} \\
\hline mean & 2.20 & 0.47 & 37.3 & 18.6 & 12.6 & 0.51 \\
\hline sd & 1.22 & 0.50 & 13.4 & 13.4 & 2.4 & 0.50 \\
\hline \multicolumn{7}{|l|}{2000} \\
\hline mean & 2.62 & 0.49 & 38.5 & 19.6 & 12.7 & 0.50 \\
\hline sd & 1.17 & 0.50 & 13.3 & 13.1 & 2.3 & 0.50 \\
\hline \multicolumn{7}{|l|}{2010} \\
\hline mean & 2.79 & 0.44 & 39.8 & 20.8 & 13.0 & 0.50 \\
\hline sd & 1.26 & 0.50 & 14.2 & 14.0 & 2.3 & 0.50 \\
\hline \multicolumn{7}{|l|}{ Total } \\
\hline mean & 2.00 & 0.43 & 38.1 & 19.8 & 12.2 & 0.51 \\
\hline sd & 1.45 & 0.49 & 14.0 & 14.0 & 2.7 & 0.50 \\
\hline$N$ & $10,316,637$ & & & & & \\
\hline \multicolumn{7}{|l|}{ Full-time } \\
\hline \multicolumn{7}{|l|}{1960} \\
\hline mean & 1.13 & 1.00 & 40.1 & 23.1 & 10.8 & 0.27 \\
\hline sd & 0.59 & 0.00 & 11.8 & 12.6 & 3.1 & 0.44 \\
\hline \multicolumn{7}{|l|}{1970} \\
\hline mean & 1.54 & 1.00 & 40.1 & 22.4 & 11.5 & 0.31 \\
\hline sd & 0.66 & 0.00 & 12.5 & 13.1 & 2.9 & 0.46 \\
\hline \multicolumn{7}{|l|}{1980} \\
\hline mean & 2.20 & 1.00 & 37.8 & 19.2 & 12.5 & 0.38 \\
\hline sd & 0.68 & 0.00 & 12.4 & 13.0 & 2.6 & 0.48 \\
\hline \multicolumn{7}{|l|}{1990} \\
\hline mean & 2.77 & 1.00 & 38.2 & 19.0 & 13.1 & 0.42 \\
\hline sd & 0.63 & 0.00 & 11.2 & 11.5 & 2.2 & 0.49 \\
\hline \multicolumn{7}{|l|}{2000} \\
\hline mean & 3.11 & 1.00 & 39.8 & 20.4 & 13.2 & 0.43 \\
\hline sd & 0.66 & 0.00 & 11.1 & 11.1 & 2.1 & 0.50 \\
\hline \multicolumn{7}{|l|}{2010} \\
\hline mean & 3.37 & 1.00 & 41.8 & 22.2 & 13.6 & 0.46 \\
\hline sd & 0.70 & 0.00 & 11.7 & 11.9 & 2.2 & 0.50 \\
\hline \multicolumn{7}{|l|}{ Total } \\
\hline mean & 2.62 & 1.00 & 39.7 & 20.8 & 12.7 & 0.40 \\
\hline sd & 0.99 & 0.00 & 11.8 & 12.1 & 2.6 & 0.49 \\
\hline$N$ & $4,314,650$ & & & & & \\
\hline
\end{tabular}

For each year, the table reports individual-level means and standard deviations of the variables named in the top row. The top segment shows everyone aged 16-65 and the bottom segment only full-time workers. 
Table A3: Estimates Using “Structural” Individual Wage Regressions (IV Second Stage)

\begin{tabular}{|c|c|c|c|c|c|c|}
\hline Full-time Empl & $\begin{array}{c}\text { (1) } \\
\text { Fgrad x100 }\end{array}$ & $\begin{array}{c}(2) \\
\text { Fgrad } x 100\end{array}$ & $\begin{array}{c}(3) \\
\operatorname{Ln}(\text { Fgrad })\end{array}$ & $\begin{array}{c}(4) \\
\text { Fgrad x100 }\end{array}$ & $\begin{array}{c}\text { (5) } \\
\text { Fgrad x100 }\end{array}$ & $\begin{array}{c}(6) \\
\text { Ln(Fgrad) }\end{array}$ \\
\hline Avg Experience & $\begin{array}{c}-0.10^{* *} \\
(0.04)\end{array}$ & $\begin{array}{c}-0.06^{* *} \\
(0.03)\end{array}$ & & $\begin{array}{c}-0.06^{* * *} \\
(0.02)\end{array}$ & $\begin{array}{c}-0.05^{* *} \\
(0.02)\end{array}$ & \\
\hline Yrs Education & & $\begin{array}{c}-0.19^{* * *} \\
(0.03)\end{array}$ & & & $\begin{array}{l}-0.03 \\
(0.02)\end{array}$ & \\
\hline Ln(Avg Exper) & & & $\begin{array}{l}-8.47^{* *} \\
(3.78)\end{array}$ & & & $\begin{array}{c}-4.28^{* * *} \\
(1.10)\end{array}$ \\
\hline Wages & Rtrn x100 & Rtrn $\times 100$ & Ln(Rtrn) & Rtrn $\times 100$ & Rtrn $x 100$ & Ln(Rtrn) \\
\hline Avg Experience & $\begin{array}{c}-0.17^{* * *} \\
(0.06)\end{array}$ & $\begin{array}{c}-0.19^{* * *} \\
(0.06)\end{array}$ & & $\begin{array}{l}-0.16^{*} \\
(0.09)\end{array}$ & $\begin{array}{c}-0.16^{* *} \\
(0.08)\end{array}$ & \\
\hline Yrs Education & & $\begin{array}{l}0.15^{*} \\
(0.09)\end{array}$ & & & $\begin{array}{c}0.00 \\
(0.06)\end{array}$ & \\
\hline Ln(Avg Exper) & & & $\begin{array}{c}-1.70^{* * *} \\
(0.62)\end{array}$ & & & $\begin{array}{l}-1.36 \\
(0.93)\end{array}$ \\
\hline Obs (Employm) & 2888 & 2888 & 2632 & 304 & 304 & 303 \\
\hline Obs (Wages) & 2888 & 2888 & 2888 & 304 & 304 & 304 \\
\hline Fixed Effects & czone+year & czone+year & czone+year & state+year & state+year & state+year \\
\hline Sample & $\geq 1980$ & $\geq 1980$ & $\geq 1980$ & $\geq 1960$ & $\geq 1960$ & $\geq 1960$ \\
\hline
\end{tabular}

The two segments display the second-stage estimates (16) for the full-time employment gradient and the wage return to experience, respectively. These are constructed here using the "structural" log-log individual-level regressions (see Section 4.2.1). Columns (1) to (3) show estimates for the panel of commuting zones over 1980-2010, columns (4) to (6) for states over 1960-2010. The first stage of the IV is very similar to the top segment of Table 3 . Robust standard errors in parentheses are clustered on state: ${ }^{*} \mathrm{p}<0.1,{ }^{* *} \mathrm{p}<0.05,{ }^{* * *} \mathrm{p}<0.01$.

Table A4: Estimates using Experienced versus Inexperienced Dummy (IV Second Stage)

\begin{tabular}{|c|c|c|c|c|c|c|}
\hline & $\begin{array}{c}(1) \\
\text { Sh Expd }\end{array}$ & $\begin{array}{c}(2) \\
\text { Rel Fullt }\end{array}$ & $\begin{array}{c}(3) \\
\text { Rel Wage }\end{array}$ & $\begin{array}{c}(4) \\
\text { Sh Expd }\end{array}$ & $\begin{array}{c}\text { (5) } \\
\text { Rel Fullt }\end{array}$ & $\begin{array}{c}(6) \\
\text { Rel Wage }\end{array}$ \\
\hline Pred Expernce & $\begin{array}{l}0.01^{* *} \\
(0.01)\end{array}$ & & & $\begin{array}{c}0.02^{* * *} \\
(0.00)\end{array}$ & & \\
\hline Share Experncd & & $\begin{array}{l}-0.46 \\
(0.33) \\
\end{array}$ & $\begin{array}{l}-0.17 \\
(0.20)\end{array}$ & & $\begin{array}{l}-0.28 \\
(0.19) \\
\end{array}$ & $\begin{array}{l}-0.22 \\
(0.24) \\
\end{array}$ \\
\hline Observations & 2888 & 2888 & 2888 & 304 & 304 & 304 \\
\hline Fixed Effects & czone+year & czone+year & czone+year & state+year & state+year & state+year \\
\hline Sample & $\geq 1980$ & $\geq 1980$ & $\geq 1980$ & $\geq 1960$ & $\geq 1960$ & $\geq 1960$ \\
\hline
\end{tabular}

The Table shows empirical results using the share of experienced workers $(\geq 20$ year of potential experience) in the individual-level regressions (14). The first column reports the first stage of the IV for commuting zones. Columns (2) and (3) report the second stage effects on the on experienced workers' relative full-time employment and wages. Columns (4)-(6) repeat this for states. Robust standard errors in parentheses are clustered on state: ${ }^{*} \mathrm{p}<0.1,{ }^{* *} \mathrm{p}<0.05,{ }^{* * *} \mathrm{p}<0.01$. 
Table A5: Estimates using State Interacted with Year Fixed Effects for Czones (IV Second Stage)

\begin{tabular}{|c|c|c|c|c|c|c|}
\hline & $\begin{array}{c}(1) \\
\text { Fgrad } \times 100\end{array}$ & $\begin{array}{c}(2) \\
\text { Fgrad } x 100\end{array}$ & $\begin{array}{c}(3) \\
\operatorname{Ln}(\text { Fgrad })\end{array}$ & $\begin{array}{c}(4) \\
\text { Rtrn } \times 100\end{array}$ & $\begin{array}{c}(5) \\
\text { Rtrn } \times 100\end{array}$ & $\begin{array}{c}(6) \\
\operatorname{Ln}(\text { Rtrn })\end{array}$ \\
\hline Avg Experience & $\begin{array}{c}-0.14^{* *} \\
(0.07)\end{array}$ & $\begin{array}{c}-0.13^{* *} \\
(0.06)\end{array}$ & & $\begin{array}{c}-0.21^{* * *} \\
(0.07)\end{array}$ & $\begin{array}{c}-0.20^{* * *} \\
(0.06)\end{array}$ & \\
\hline Yrs Education & & $\begin{array}{c}-0.28^{* * *} \\
(0.10)\end{array}$ & & & $\begin{array}{c}-0.23^{* *} \\
(0.09)\end{array}$ & \\
\hline Ln(Avg Exper) & & & $\begin{array}{c}-14.60^{* *} \\
(6.66)\end{array}$ & & & $\begin{array}{c}-3.27^{* * *} \\
(1.06)\end{array}$ \\
\hline Observations & 2888 & 2888 & 2632 & 2888 & 2888 & 2888 \\
\hline Fixed Effects & cz;stateXyr & cz;stateXyr & cz;stateXyr & cz;stateXyr & cz;stateXyr & cz;stateXyr \\
\hline Sample & $\geq 1980$ & $\geq 1980$ & $\geq 1980$ & $\geq 1960$ & $\geq 1960$ & $\geq 1960$ \\
\hline
\end{tabular}

The table reports results when we control for state $\times$ year fixed effects in regressions on the commuting zone level, whereby overlapping commuting zones are assigned to the state with the highest share of employment. The first stage of the IV remains substantial but is for brevity not shown. Robust standard errors in parentheses are clustered on czone: ${ }^{*} \mathrm{p}<0.1,{ }^{* *} \mathrm{p}<0.05,{ }^{* * *} \mathrm{p}<0.01$.

Table A6: Estimates using First-Differenced Model (IV Second Stage)

\begin{tabular}{|c|c|c|c|c|c|c|}
\hline Full-time Empl & $\begin{array}{c}(1) \\
\Delta(\text { Fgr } \times 100)\end{array}$ & $\begin{array}{c}(2) \\
\Delta(\text { Fgr } \times 100)\end{array}$ & $\begin{array}{c}(3) \\
\Delta \operatorname{Ln}(\mathrm{Fgr})\end{array}$ & $\begin{array}{c}(4) \\
\Delta(\text { Fgr } \times 100)\end{array}$ & $\begin{array}{c}(5) \\
\Delta(\text { Fgr } \times 100)\end{array}$ & $\begin{array}{c}(6) \\
\Delta \operatorname{Ln}(\mathrm{Fgr})\end{array}$ \\
\hline$\Delta$ Avg Exper & $\begin{array}{l}-0.08 \\
(0.06)\end{array}$ & $\begin{array}{l}-0.05 \\
(0.04)\end{array}$ & & $\begin{array}{l}-0.05 \\
(0.05)\end{array}$ & $\begin{array}{l}-0.05 \\
(0.05)\end{array}$ & \\
\hline$\Delta$ Yrs Educatn & & $\begin{array}{c}-0.14^{* * *} \\
(0.03)\end{array}$ & & & $\begin{array}{l}-0.00 \\
(0.03)\end{array}$ & \\
\hline$\Delta \operatorname{Ln}($ Avg Exp) & & & $\begin{array}{l}-7.45 \\
(5.23)\end{array}$ & & & $\begin{array}{l}-5.89 \\
(4.45)\end{array}$ \\
\hline Wages & $\Delta(\operatorname{Rtr} \times 100)$ & $\Delta(\operatorname{Rtr} \times 100)$ & $\Delta \operatorname{Ln}(\operatorname{Rtr})$ & $\Delta(\operatorname{Rtr} \times 100)$ & $\Delta(\operatorname{Rtr} \times 100)$ & $\Delta \operatorname{Ln}(\operatorname{Rtr})$ \\
\hline$\Delta$ Avg Exper & $\begin{array}{c}-0.17^{* * *} \\
(0.06)\end{array}$ & $\begin{array}{c}-0.18^{* * *} \\
(0.05)\end{array}$ & & $\begin{array}{l}-0.16^{*} \\
(0.08)\end{array}$ & $\begin{array}{c}-0.18^{* *} \\
(0.08)\end{array}$ & \\
\hline$\Delta$ Yrs Educatn & & $\begin{array}{c}0.03 \\
(0.05)\end{array}$ & & & $\begin{array}{c}0.07 \\
(0.08)\end{array}$ & \\
\hline$\Delta \operatorname{Ln}($ Avg Exp) & & & $\begin{array}{c}-2.73^{* * *} \\
(0.92)\end{array}$ & & & $\begin{array}{l}-2.85^{* *} \\
(1.39)\end{array}$ \\
\hline Obs (Fullt Emp) & 2166 & 2166 & 1805 & 253 & 253 & 251 \\
\hline Obs (F-S\&Wage) & 2166 & 2166 & 2166 & 253 & 253 & 253 \\
\hline Fixed Effects & year & year & year & year & year & year \\
\hline Sample & $\geq 1980$ & $\geq 1980$ & $\geq 1980$ & $\geq 1960$ & $\geq 1960$ & $\geq 1960$ \\
\hline
\end{tabular}

The table reports results when the model is estimated in first differences. The two segments display the second-stage estimates (16) for the change of the full-time employment gradient and the wage return to experience, respectively. Columns (1) to (3) show estimates for the panel of commuting zones over 19902010, columns (4) to (6) for states over 1970-2010. Robust standard errors in parentheses are clustered on state: ${ }^{*} \mathrm{p}<0.1,{ }^{* *} \mathrm{p}<0.05,{ }^{* *} \mathrm{p}<0.01$. 
Table A7: Full-Time Empl. Gradient and Wage Return to Experience (IV, Add. Controls)

\begin{tabular}{lcccccc}
\hline \hline First Stage & $(1)$ & $(2)$ & $(3)$ & $(4)$ & $(5)$ & $(6)$ \\
Expernce & Expernce & Ln(Exper) & $\begin{array}{c}(5) \\
\text { Expernce }\end{array}$ & $\begin{array}{c}\text { Expernce } \\
\text { Ln(Exper) }\end{array}$ \\
\hline Pred Expernce & $0.54^{* * *}$ & $0.57^{* * *}$ & & $0.45^{* * *}$ & $0.61^{* * *}$ & \\
Sh. Goods Ind & $(0.15)$ & $(0.13)$ & & $(0.07)$ & $(0.06)$ & \\
& -2.43 & -2.86 & -0.07 & -0.53 & -1.24 & -0.04 \\
Sh. Routine Occ & $(2.03)$ & $(1.87)$ & $(0.10)$ & $(1.70)$ & $(1.33)$ & $(0.09)$ \\
& $8.54^{* * *}$ & $5.76^{* *}$ & $0.38^{* *}$ & $7.47^{* * *}$ & $4.99^{* *}$ & $0.38^{* *}$ \\
Share Black & $(2.94)$ & $(2.38)$ & $(0.15)$ & $(2.73)$ & $(2.17)$ & $(0.14)$ \\
& & 0.19 & & & $4.78^{* * *}$ & \\
Share Female & & $(1.71)$ & & & $(1.41)$ & \\
& & $6.37^{* * *}$ & & & $4.67^{* *}$ & \\
Yrs Education & & $(1.93)$ & & & $-0.77^{* * *}$ & \\
& & $-1.02^{* * *}$ & & & $(0.15)$ & \\
Ln(Pred Exper) & & $(0.27)$ & & & & $0.48^{* * *}$ \\
& & & $0.53^{* * *}$ & & & $(0.07)$
\end{tabular}

\begin{tabular}{lcccccc} 
Full-time Empl & Fgrad x100 & Fgrad x100 & Ln(Fgrad) & Fgrad x100 & Fgrad x100 & Ln(Fgrad) \\
\hline Avg Experience & $-0.08^{* *}$ & $-0.06^{* *}$ & & $-0.08^{* * *}$ & $-0.09^{* * *}$ & \\
& $(0.03)$ & $(0.02)$ & & $(0.03)$ & $(0.02)$ & \\
Sh. Goods Ind & 0.03 & -0.19 & 0.23 & 0.20 & 0.31 & 0.32 \\
& $(0.21)$ & $(0.18)$ & $(0.96)$ & $(0.26)$ & $(0.22)$ & $(0.81)$ \\
Sh. Routine Occ & $1.06^{* * *}$ & $0.48^{*}$ & $4.08^{* * *}$ & $0.77^{*}$ & $1.01^{* *}$ & 2.70 \\
& $(0.31)$ & $(0.26)$ & $(1.47)$ & $(0.43)$ & $(0.40)$ & $(1.90)$ \\
Share Black & & 0.27 & & & $0.69^{*}$ & \\
& & $(0.36)$ & & & $(0.37)$ & \\
Share Female & & 0.10 & & & -0.08 & \\
& & $(0.22)$ & & & $0.45)$ & \\
Yrs Education & & $-0.18^{* * *}$ & & 0.02 & \\
& & $(0.03)$ & & & & $-5.02)$ \\
Ln(Avg Exper) & & & $-7.45^{* *}$ & & & $(1.38)$
\end{tabular}

\begin{tabular}{|c|c|c|c|c|c|c|}
\hline Wages & Rtrn $x 100$ & Rtrn x100 & Ln(Rtrn) & Rtrn $x 100$ & Rtrn x100 & Ln(Rtrn) \\
\hline Avg Experience & $\begin{array}{c}-0.08^{* * *} \\
(0.02)\end{array}$ & $\begin{array}{c}-0.08^{* * *} \\
(0.02)\end{array}$ & & $\begin{array}{l}-0.05 \\
(0.04)\end{array}$ & $\begin{array}{l}-0.06^{*} \\
(0.04)\end{array}$ & \\
\hline Sh. Goods Ind & $\begin{array}{c}-0.68^{* * *} \\
(0.21)\end{array}$ & $\begin{array}{c}-0.66^{* * * *} \\
(0.18)\end{array}$ & $\begin{array}{c}-0.52^{* * *} \\
(0.16)\end{array}$ & $\begin{array}{l}-0.87^{*} \\
(0.49)\end{array}$ & $\begin{array}{l}-0.86^{* *} \\
(0.44)\end{array}$ & $\begin{array}{c}-0.87^{* *} \\
(0.35)\end{array}$ \\
\hline Sh. Routine Occ & $\begin{array}{c}0.09 \\
(0.31)\end{array}$ & $\begin{array}{c}0.25 \\
(0.31)\end{array}$ & $\begin{array}{c}0.16 \\
(0.23)\end{array}$ & $\begin{array}{c}1.30 \\
(0.79)\end{array}$ & $\begin{array}{l}1.25^{*} \\
(0.75)\end{array}$ & $\begin{array}{l}1.46^{* *} \\
(0.67)\end{array}$ \\
\hline Share Black & & $\begin{array}{c}0.05 \\
(0.53)\end{array}$ & & & $\begin{array}{l}-0.80 \\
(0.59)\end{array}$ & \\
\hline Share Female & & $\begin{array}{l}-0.27 \\
(0.36)\end{array}$ & & & $\begin{array}{c}0.50 \\
(0.77)\end{array}$ & \\
\hline Yrs Education & & $\begin{array}{c}0.05 \\
(0.05)\end{array}$ & & & $\begin{array}{c}0.02 \\
(0.04)\end{array}$ & \\
\hline Ln(Avg Exper) & & & $\begin{array}{c}-1.21^{* * *} \\
(0.39)\end{array}$ & & & $\begin{array}{l}-0.69 \\
(0.70) \\
\end{array}$ \\
\hline Obs (Fullt Emp) & 2888 & 2888 & 2632 & 304 & 304 & 303 \\
\hline Obs (F-S\&Wage) & 2888 & 2888 & 2888 & 304 & 304 & 304 \\
\hline$R^{2}$ (First Stage) & 0.91 & 0.92 & 0.91 & 0.96 & 0.96 & 0.96 \\
\hline Fixed Effects & $\begin{array}{l}\text { czone+year } \\
\geq 1980\end{array}$ & $\begin{array}{l}\text { czone+year } \\
>1980\end{array}$ & $\begin{array}{l}\text { czone+year } \\
>1980\end{array}$ & $\begin{array}{l}\text { state+year } \\
>1960\end{array}$ & $\begin{array}{l}\text { state+year } \\
>1960\end{array}$ & $\begin{array}{l}\text { state+year } \\
>1960\end{array}$ \\
\hline & $\geq 1980$ & $\geq 1980$ & $\geq 1980$ & $\geq 1960$ & $\geq 1960$ & $\geq 1960$ \\
\hline
\end{tabular}

The top segment of the table reports the regression of full-time workers' average experience onto its own prediction from the census 10 years prior (first-stage of the IV). The middle and bottom segments display the second-stage estimates (16) for the full-time employment gradient and the wage return to experience, respectively. Columns (1) to (3) show estimates for the panel of commuting zones over 1980-2010, columns (4) to (6) for states over 1960-2010. Robust standard errors in parentheses are clustered on state: ${ }^{*} \mathrm{p}<0.1,{ }^{* *}$ $\mathrm{p}<0.05,{ }^{* * *} \mathrm{p}<0.01$. 
Table A8: Estimates using Males only Sample (IV Second Stage)

\begin{tabular}{|c|c|c|c|c|c|c|}
\hline Full-time Empl & $\begin{array}{c}\text { (1) } \\
\text { Fgrad } \times 100\end{array}$ & $\begin{array}{c}(2) \\
\text { Fgrad } x 100\end{array}$ & $\begin{array}{c}(3) \\
\text { Ln(Fgrad) }\end{array}$ & $\begin{array}{c}(4) \\
\text { Fgrad } \times 100\end{array}$ & $\begin{array}{c}\text { (5) } \\
\text { Fgrad } \times 100\end{array}$ & $\begin{array}{c}(6) \\
\text { Ln(Fgrad })\end{array}$ \\
\hline Avg Experience & $\begin{array}{l}-0.13^{*} \\
(0.08)\end{array}$ & $\begin{array}{l}-0.09^{*} \\
(0.04)\end{array}$ & & $\begin{array}{c}-0.09^{* * *} \\
(0.03)\end{array}$ & $\begin{array}{c}-0.07^{* *} \\
(0.03)\end{array}$ & \\
\hline Yrs Education & & $\begin{array}{c}-0.20^{* * *} \\
(0.04)\end{array}$ & & & $\begin{array}{l}-0.05^{*} \\
(0.03)\end{array}$ & \\
\hline Ln(Avg Exper) & & & $\begin{array}{c}-9.37^{* *} \\
(4.24)\end{array}$ & & & $\begin{array}{c}-6.43^{* * *} \\
(1.89)\end{array}$ \\
\hline Wages & Rtrn x100 & Rtrn x100 & Ln(Rtrn) & Rtrn x100 & Rtrn x100 & Ln(Rtrn) \\
\hline Avg Experience & $\begin{array}{c}-0.10^{* *} \\
(0.05)\end{array}$ & $\begin{array}{c}-0.13^{* * *} \\
(0.05)\end{array}$ & & $\begin{array}{l}-0.09 \\
(0.06)\end{array}$ & $\begin{array}{l}-0.10 \\
(0.06)\end{array}$ & \\
\hline Yrs Education & & $\begin{array}{l}0.14^{* *} \\
(0.06)\end{array}$ & & & $\begin{array}{c}0.03 \\
(0.04)\end{array}$ & \\
\hline Ln(Avg Exper) & & & $\begin{array}{c}-1.27^{* *} \\
(0.63)\end{array}$ & & & $\begin{array}{l}-1.28 \\
(1.01)\end{array}$ \\
\hline Obs (Employm) & 2888 & 2888 & 2597 & 304 & 304 & 304 \\
\hline Obs (Wages) & 2888 & 2888 & 2888 & 304 & 304 & 304 \\
\hline Fixed Effects & czone+year & czone+year & czone+year & state+year & state+year & state+year \\
\hline Sample & $\geq 1980$ & $\geq 1980$ & $\geq 1980$ & $\geq 1960$ & $\geq 1960$ & $\geq 1960$ \\
\hline
\end{tabular}

The table reports results when the whole analysis is restricted to males. The two segments display the second-stage estimates (16) for the full-time employment gradient and the wage return to experience, respectively. Columns (1) to (3) show estimates for the panel of commuting zones over 1980-2010, columns (4) to (6) for states over 1960-2010. Robust standard errors in parentheses are clustered on state: ${ }^{*} \mathrm{p}<0.1,{ }^{* *}$ $\mathrm{p}<0.05,{ }^{* * *} \mathrm{p}<0.01$.

Table A9: Estimates using DFL Reweighted Sample (IV Second Stage)

\begin{tabular}{|c|c|c|c|c|c|c|}
\hline Full-time Empl & $\begin{array}{c}(1) \\
\text { Fgrad } x 100\end{array}$ & $\begin{array}{c}(2) \\
\text { Fgrad } x 100\end{array}$ & $\begin{array}{c}(3) \\
\text { Ln(Fgrad) }\end{array}$ & $\begin{array}{c}(4) \\
\text { Fgrad } x 100\end{array}$ & $\begin{array}{c}\text { (5) } \\
\text { Fgrad } x 100\end{array}$ & $\begin{array}{c}(6) \\
\text { Ln(Fgrad) }\end{array}$ \\
\hline Avg Experience & $\begin{array}{l}-0.05^{*} \\
(0.03)\end{array}$ & $\begin{array}{l}-0.02^{*} \\
(0.01)\end{array}$ & & $\begin{array}{c}-0.06^{* *} \\
(0.03)\end{array}$ & $\begin{array}{l}-0.04^{*} \\
(0.03)\end{array}$ & \\
\hline Yrs Education & & $\begin{array}{c}-0.16^{* * *} \\
(0.02)\end{array}$ & & & $\begin{array}{c}-0.04^{* *} \\
(0.02)\end{array}$ & \\
\hline Ln(Avg Exper) & & & $\begin{array}{l}-4.61^{*} \\
(2.65) \\
\end{array}$ & & & $\begin{array}{c}-4.02^{* * *} \\
(1.38)\end{array}$ \\
\hline Wages & Rtrn x100 & Rtrn x100 & Ln(Rtrn) & Rtrn x100 & Rtrn x100 & Ln(Rtrn) \\
\hline Avg Experience & $\begin{array}{c}-0.07^{* *} \\
(0.03)\end{array}$ & $\begin{array}{c}-0.08^{* * *} \\
(0.03)\end{array}$ & & $\begin{array}{c}-0.02 \\
(0.03)\end{array}$ & $\begin{array}{c}-0.02 \\
(0.02)\end{array}$ & \\
\hline Yrs Education & & $\begin{array}{c}0.06 \\
(0.05)\end{array}$ & & & $\begin{array}{l}-0.00 \\
(0.03)\end{array}$ & \\
\hline Ln(Avg Exper) & & & $\begin{array}{c}-1.17^{* *} \\
(0.47)\end{array}$ & & & $\begin{array}{c}0.09 \\
(0.51) \\
\end{array}$ \\
\hline Obs (Employm) & 2888 & 2888 & 2609 & 304 & 304 & 302 \\
\hline Obs (Wages) & 2888 & 2888 & 2881 & 304 & 304 & 304 \\
\hline $\begin{array}{l}\text { Fixed Effects } \\
\text { Sample }\end{array}$ & $\begin{array}{c}\text { czone+year } \\
\geq 1980\end{array}$ & $\begin{array}{c}\text { czone+year } \\
\geq 1980\end{array}$ & $\begin{array}{c}\text { czone+year } \\
\geq 1980\end{array}$ & $\begin{array}{c}\text { state+year } \\
\geq 1960\end{array}$ & $\begin{array}{c}\text { state+year } \\
\geq 1960\end{array}$ & $\begin{array}{l}\text { state+year } \\
\quad \geq 1960\end{array}$ \\
\hline
\end{tabular}

The table reports the results when, for the estimation at the micro-level, the sample is reweighed to keep the composition of individuals within each local labor market-year the same as in 1980. The two segments display the second-stage estimates (16) for the full-time employment gradient and the wage return to experience, respectively. Columns (1) to (3) show estimates for the panel of commuting zones over 19802010, columns (4) to (6) for states over 1960-2010. The first stage of the IV is very similar to the top segment of Table 3. Robust standard errors in parentheses are clustered on state: ${ }^{*} p<0.1,{ }^{* *} p<0.05,{ }^{* * *} p<0.01$. 
Table A10: Estimates Separately for High-School and College Sample (IV Second Stage)

\begin{tabular}{|c|c|c|c|c|c|c|}
\hline Empl, High-Sch & $\begin{array}{c}1) \\
\text { Fgrad } x 100\end{array}$ & $\begin{array}{c}(2) \\
\text { Fgrad } x 100\end{array}$ & $\begin{array}{c}(3) \\
\text { Ln(Fgrad) }\end{array}$ & $\begin{array}{c}(4) \\
\text { Fgrad } x 100\end{array}$ & $\begin{array}{c}(5) \\
\text { Fgrad } x 100\end{array}$ & $\begin{array}{c}(6) \\
\text { Ln(Fgrad) }\end{array}$ \\
\hline Avg Experience & $\begin{array}{c}-0.13^{* * *} \\
(0.03)\end{array}$ & $\begin{array}{c}-0.09^{* * *} \\
(0.03)\end{array}$ & & $\begin{array}{l}-0.10^{*} \\
(0.06)\end{array}$ & $\begin{array}{l}-0.31 \\
(0.49)\end{array}$ & \\
\hline Yrs Education & & $\begin{array}{c}-0.12^{* * *} \\
(0.04)\end{array}$ & & & $\begin{array}{c}0.34 \\
(0.70)\end{array}$ & \\
\hline Ln(Avg Exper) & & & $\begin{array}{l}-7.55^{* * *} \\
(2.00)\end{array}$ & & & $\begin{array}{l}-4.88^{* *} \\
(2.49)\end{array}$ \\
\hline Wages, High-Sch & Rtrn x100 & Rtrn x100 & Ln(Rtrn) & Rtrn x100 & Rtrn x100 & Ln(Rtrn) \\
\hline Avg Experience & $\begin{array}{c}-0.11^{* * *} \\
(0.04)\end{array}$ & $\begin{array}{c}-0.13^{* * *} \\
(0.04)\end{array}$ & & $\begin{array}{l}-0.07 \\
(0.05)\end{array}$ & $\begin{array}{c}-0.16 \\
(0.25)\end{array}$ & \\
\hline Yrs Education & & $\begin{array}{c}0.07 \\
(0.08)\end{array}$ & & & $\begin{array}{c}0.16 \\
(0.36)\end{array}$ & \\
\hline Ln(Avg Exper) & & & $\begin{array}{c}-1.63^{* *} \\
(0.65)\end{array}$ & & & $\begin{array}{c}-0.69 \\
(1.05) \\
\end{array}$ \\
\hline Empl, College & Fgrad x100 & Fgrad x100 & Ln(Fgrad) & Fgrad x100 & Fgrad x100 & Ln(Fgrad) \\
\hline Avg Experience & $\begin{array}{c}-0.07^{* * *} \\
(0.03)\end{array}$ & $\begin{array}{c}-0.08^{* * *} \\
(0.03)\end{array}$ & & $\begin{array}{c}-0.12^{* * *} \\
(0.03)\end{array}$ & $\begin{array}{c}-0.16^{* * *} \\
(0.04)\end{array}$ & \\
\hline Yrs Education & & $\begin{array}{c}-0.27^{* * *} \\
(0.09)\end{array}$ & & & $\begin{array}{l}-0.48^{* * *} \\
(0.18)\end{array}$ & \\
\hline Ln(Avg Exper) & & & $\begin{array}{c}-14.31^{* * *} \\
(5.29)\end{array}$ & & & $\begin{array}{c}-12.13^{* * *} \\
(3.36) \\
\end{array}$ \\
\hline Wages, College & Rtrn x100 & Rtrn x100 & Ln(Rtrn) & Rtrn x100 & Rtrn x100 & Ln(Rtrn) \\
\hline Avg Experience & $\begin{array}{l}-0.06^{*} \\
(0.04)\end{array}$ & $\begin{array}{l}-0.07^{*} \\
(0.04)\end{array}$ & & $\begin{array}{l}-0.05 \\
(0.05)\end{array}$ & $\begin{array}{l}-0.10 \\
(0.07)\end{array}$ & \\
\hline Yrs Education & & $\begin{array}{c}-0.23^{*} \\
(0.13)\end{array}$ & & & $\begin{array}{c}-0.57^{*} \\
(0.31)\end{array}$ & \\
\hline Ln(Avg Exper) & & & $\begin{array}{c}-1.03^{* *} \\
(0.47)\end{array}$ & & & $\begin{array}{l}-0.37 \\
(0.59) \\
\end{array}$ \\
\hline Obs (Empl,HS) & 2888 & 2888 & 2801 & 304 & 304 & 304 \\
\hline Obs (Wage,HS) & 2888 & 2882 & 2888 & 304 & 304 & 304 \\
\hline Obs (Empl,Col) & 2888 & 2888 & 1500 & 304 & 304 & 259 \\
\hline Obs (Wage,Col) & 2888 & 2888 & 2869 & 304 & 304 & 304 \\
\hline $\begin{array}{l}\text { Fixed Effects } \\
\text { Sample }\end{array}$ & $\begin{array}{c}\text { czone+year } \\
\geq 1980\end{array}$ & $\begin{array}{c}\text { czone+year } \\
\geq 1980\end{array}$ & $\begin{array}{c}\text { czone+year } \\
\geq 1980\end{array}$ & $\begin{array}{l}\text { state+year } \\
\geq 1960\end{array}$ & $\begin{array}{l}\text { state+year } \\
\geq 1960\end{array}$ & $\begin{array}{l}\text { state+year } \\
\quad \geq 1960\end{array}$ \\
\hline
\end{tabular}

The table reports results when the whole analysis split by workers' education. The first two segments display for the subsample of high-school workers the second-stage estimates (16) for the full-time employment gradient and the wage return to experience, respectively. The bottom two segments show the estimates for the subsample of college workers. Columns (1) to (3) show estimates for the panel of commuting zones over 1980-2010, columns (4) to (6) for states over 1960-2010. Robust standard errors in parentheses are clustered on state: ${ }^{*} \mathrm{p}<0.1,{ }^{* *} \mathrm{p}<0.05,{ }^{* * *} \mathrm{p}<0.01$. 
Table A11: Descriptive Statistics for the Czone and State Panels (Additional Variables)

\begin{tabular}{|c|c|c|c|c|c|c|c|}
\hline Czone Panel & Emplnt & LF-Particp & Unemplnt & Disablty & Welfare & Soc-Secrty & In-Migrtn \\
\hline $\begin{array}{l}1980 \\
\text { mean } \\
\text { sd }\end{array}$ & $\begin{array}{l}0.08 \\
0.17\end{array}$ & $\begin{array}{c}-0.05 \\
0.17\end{array}$ & $\begin{array}{l}-0.12 \\
0.04\end{array}$ & $\begin{array}{l}0.41 \\
0.09\end{array}$ & $\begin{array}{c}-0.01 \\
0.03\end{array}$ & $\begin{array}{l}0.46 \\
0.09\end{array}$ & $\begin{array}{c}-0.44 \\
0.21\end{array}$ \\
\hline $\begin{array}{l}1990 \\
\text { mean } \\
\text { sd }\end{array}$ & $\begin{array}{c}-0.04 \\
0.18\end{array}$ & $\begin{array}{c}-0.17 \\
0.17\end{array}$ & $\begin{array}{c}-0.13 \\
0.04\end{array}$ & $\begin{array}{l}0.38 \\
0.08\end{array}$ & $\begin{array}{l}0.00 \\
0.04\end{array}$ & $\begin{array}{l}0.50 \\
0.10\end{array}$ & $\begin{array}{c}-0.47 \\
0.20\end{array}$ \\
\hline $\begin{array}{l}2000 \\
\text { mean } \\
\text { sd }\end{array}$ & $\begin{array}{c}-0.03 \\
0.17 \\
\end{array}$ & $\begin{array}{c}-0.16 \\
0.17 \\
\end{array}$ & $\begin{array}{c}-0.13 \\
0.04 \\
\end{array}$ & $\begin{array}{l}0.21 \\
0.07\end{array}$ & $\begin{array}{l}0.06 \\
0.03\end{array}$ & $\begin{array}{l}0.46 \\
0.11\end{array}$ & $\begin{array}{c}-0.53 \\
0.20\end{array}$ \\
\hline $\begin{array}{l}2010 \\
\text { mean } \\
\text { sd }\end{array}$ & $\begin{array}{l}0.13 \\
0.16\end{array}$ & $\begin{array}{l}0.00 \\
0.19\end{array}$ & $\begin{array}{c}-0.13 \\
0.06\end{array}$ & $\begin{array}{l}0.39 \\
0.11\end{array}$ & $\begin{array}{l}0.07 \\
0.03\end{array}$ & $\begin{array}{l}0.49 \\
0.13\end{array}$ & $\begin{array}{c}-0.16 \\
0.08\end{array}$ \\
\hline $\begin{array}{l}\text { Total } \\
\text { mean } \\
\text { sd }\end{array}$ & $\begin{array}{l}0.04 \\
0.19 \\
\end{array}$ & $\begin{array}{c}-0.09 \\
0.19 \\
\end{array}$ & $\begin{array}{c}-0.13 \\
0.05 \\
\end{array}$ & $\begin{array}{l}0.35 \\
0.12 \\
\end{array}$ & $\begin{array}{l}0.04 \\
0.05 \\
\end{array}$ & $\begin{array}{l}0.48 \\
0.11 \\
\end{array}$ & $\begin{array}{c}-0.38 \\
0.23 \\
\end{array}$ \\
\hline$N$ & 2888 & & & & & & \\
\hline State Panel & & & & & & & \\
\hline $\begin{array}{l}1960 \\
\text { mean } \\
\text { sd }\end{array}$ & $\begin{array}{l}0.37 \\
0.08\end{array}$ & $\begin{array}{l}0.32 \\
0.07\end{array}$ & $\begin{array}{c}-0.05 \\
0.02\end{array}$ & . & . &. & $\begin{array}{c}-0.36 \\
0.13\end{array}$ \\
\hline $\begin{array}{l}1970 \\
\text { mean } \\
\text { sd }\end{array}$ & $\begin{array}{l}0.39 \\
0.08\end{array}$ & $\begin{array}{l}0.33 \\
0.09\end{array}$ & $\begin{array}{c}-0.06 \\
0.02 \\
\end{array}$ & $\begin{array}{l}0.34 \\
0.06\end{array}$ & $\begin{array}{l}0.00 \\
0.02\end{array}$ & $\begin{array}{l}0.25 \\
0.04\end{array}$ & $\begin{array}{c}-0.40 \\
0.10\end{array}$ \\
\hline $\begin{array}{l}1980 \\
\text { mean } \\
\text { sd }\end{array}$ & $\begin{array}{l}0.08 \\
0.14 \\
\end{array}$ & $\begin{array}{c}-0.05 \\
0.14\end{array}$ & $\begin{array}{c}-0.12 \\
0.03\end{array}$ & $\begin{array}{l}0.42 \\
0.07\end{array}$ & $\begin{array}{c}-0.01 \\
0.02\end{array}$ & $\begin{array}{l}0.40 \\
0.06\end{array}$ & $\begin{array}{c}-0.30 \\
0.12\end{array}$ \\
\hline $\begin{array}{l}1990 \\
\text { mean } \\
\text { sd }\end{array}$ & $\begin{array}{c}-0.04 \\
0.12\end{array}$ & $\begin{array}{c}-0.17 \\
0.11\end{array}$ & $\begin{array}{c}-0.13 \\
0.03\end{array}$ & $\begin{array}{l}0.39 \\
0.06\end{array}$ & $\begin{array}{l}0.00 \\
0.03\end{array}$ & $\begin{array}{l}0.47 \\
0.06\end{array}$ & $\begin{array}{c}-0.34 \\
0.12\end{array}$ \\
\hline $\begin{array}{l}2000 \\
\text { mean } \\
\text { sd }\end{array}$ & $\begin{array}{c}-0.03 \\
0.11\end{array}$ & $\begin{array}{c}-0.16 \\
0.12 \\
\end{array}$ & $\begin{array}{c}-0.13 \\
0.03\end{array}$ & $\begin{array}{l}0.22 \\
0.04\end{array}$ & $\begin{array}{l}0.06 \\
0.02\end{array}$ & $\begin{array}{l}0.44 \\
0.07\end{array}$ & $\begin{array}{c}-0.38 \\
0.11 \\
\end{array}$ \\
\hline $\begin{array}{l}2010 \\
\text { mean } \\
\text { sd }\end{array}$ & $\begin{array}{l}0.13 \\
0.11\end{array}$ & $\begin{array}{l}0.00 \\
0.13\end{array}$ & $\begin{array}{c}-0.13 \\
0.03\end{array}$ & $\begin{array}{l}0.39 \\
0.08\end{array}$ & $\begin{array}{l}0.07 \\
0.02\end{array}$ & $\begin{array}{l}0.47 \\
0.09\end{array}$ & $\begin{array}{c}-0.12 \\
0.05\end{array}$ \\
\hline $\begin{array}{l}\text { Total } \\
\text { mean } \\
\text { sd }\end{array}$ & $\begin{array}{l}0.12 \\
0.20\end{array}$ & $\begin{array}{l}0.01 \\
0.22\end{array}$ & $\begin{array}{c}-0.11 \\
0.04\end{array}$ & $\begin{array}{l}0.35 \\
0.10\end{array}$ & $\begin{array}{l}0.03 \\
0.04\end{array}$ & $\begin{array}{l}0.42 \\
0.10\end{array}$ & $\begin{array}{c}-0.30 \\
0.15\end{array}$ \\
\hline$N$ & 304 & & & & & & \\
\hline
\end{tabular}

For each year, the table shows local labor market (LLM) level means and standard deviations of the variables named in the top row. The variables are all experience gradients from regression (14), i.e. with regard to employment (full-time or parttime), labor force participation, unemployment, disability (self-identified), welfare income (including GA and SSI), social security income (including pensions and disability), and in-migration into the LLM in question. Information on disability as well as welfare and social security claims are not available in 1960 . We also harmonized somewhat different definitions of disability and migration for 2010 with the previous years. 
Figure A1: The Distribution of Average Working Age across U.S. Czones and Time

(a) Average Age of Full-time Workers 1970

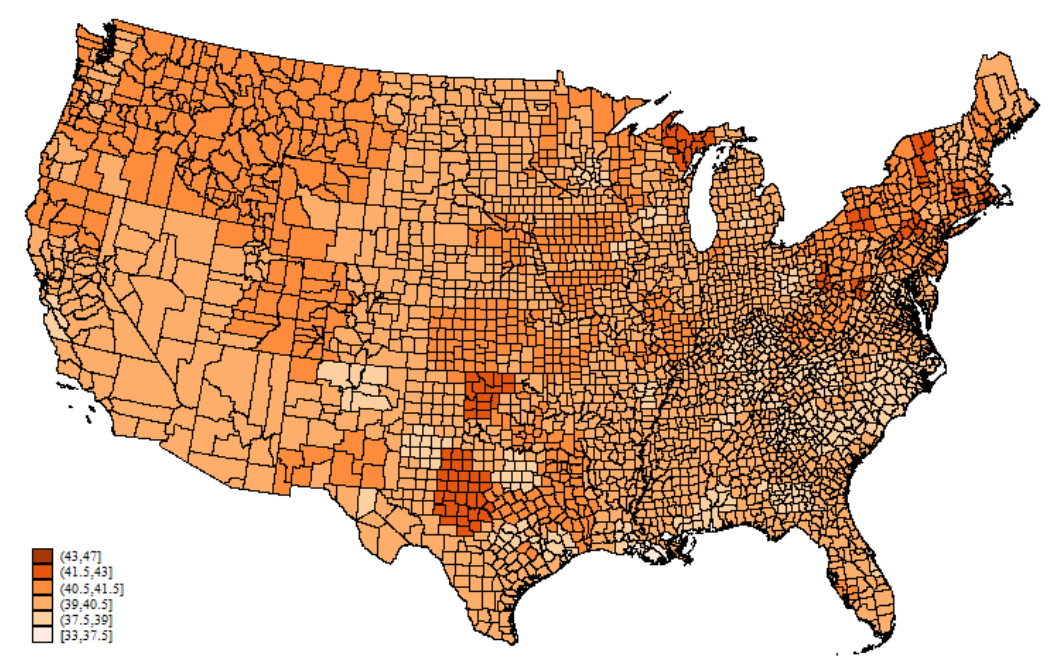

(b) Average Age of Full-time Workers 1990

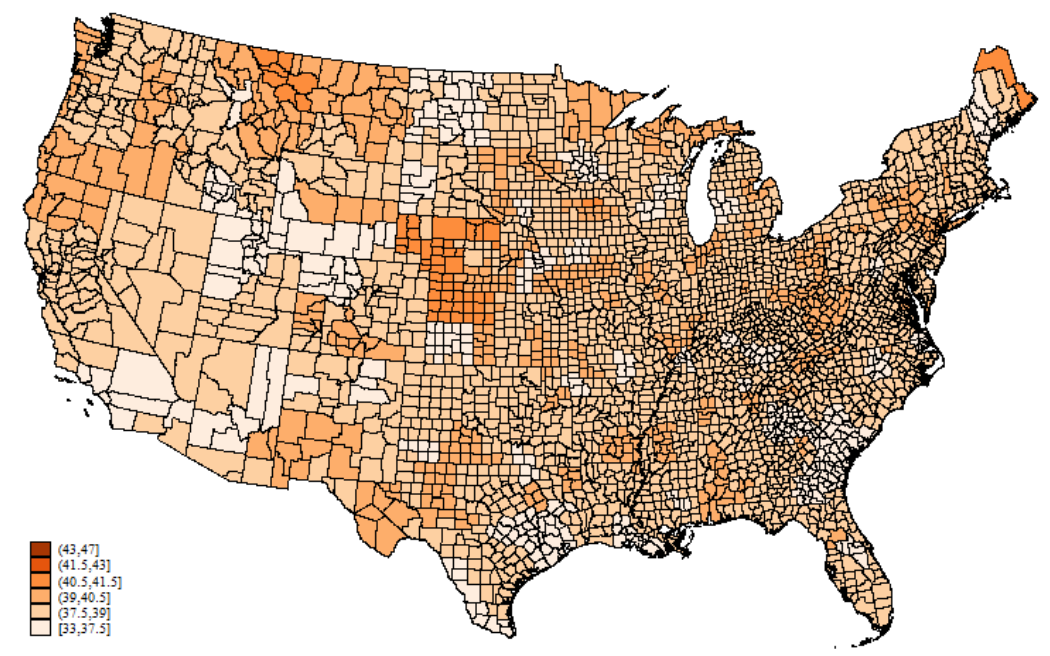

(c) Average Age of Full-time Workers 2010

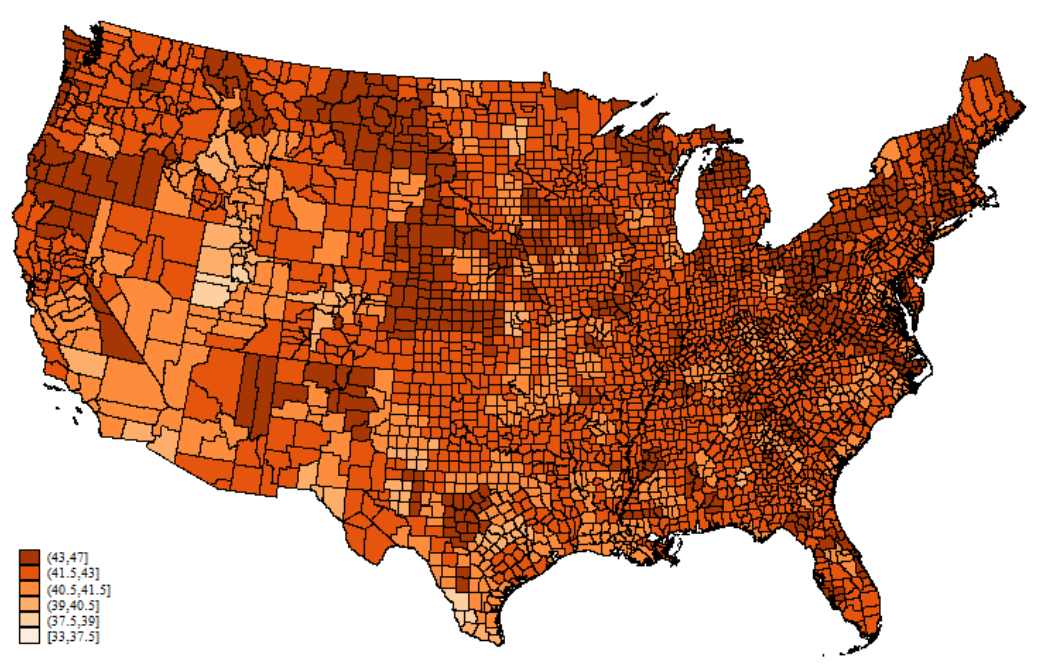


Figure A2: The Race Between Supply of Experience and Other Factors (State Estimates)

(a) The Aggregate Wage Return to Experience

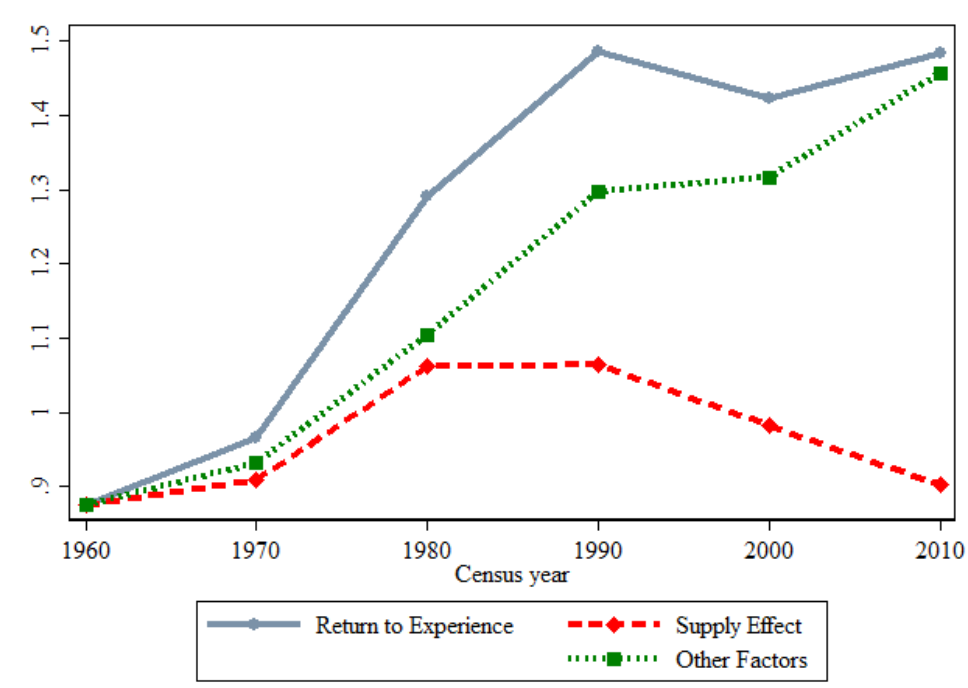

(b) The Aggregate Full-time Employment Gradient of Experience

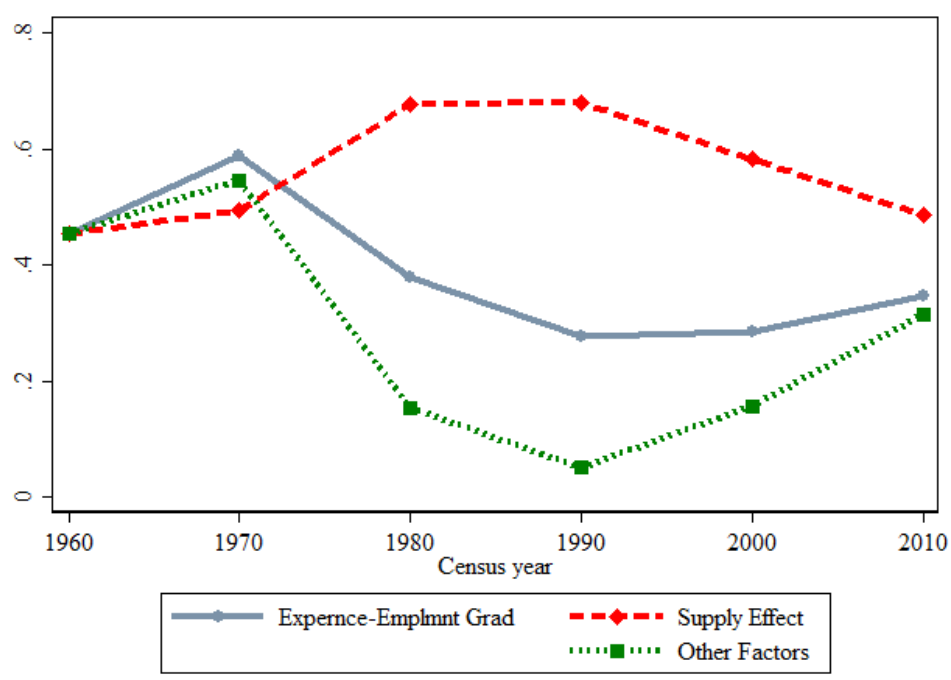

Supply effect and other factors (including demand) using the IV estimates for the panel of states in 1960-2010 (column (4) of Table 3). 